\title{
A statistical analysis of the influence of deep convection on water vapor variability in the tropical upper troposphere
}

\author{
J. S. Wright ${ }^{1}$, R. Fu ${ }^{2}$, and A. J. Heymsfield ${ }^{3}$ \\ ${ }^{1}$ Department of Applied Physics and Applied Mathematics, Columbia University, New York, NY, USA \\ ${ }^{2}$ Jackson School of Geosciences, University of Texas, Austin, TX, USA \\ ${ }^{3}$ National Center for Atmospheric Research, Boulder, CO, USA
}

Received: 16 December 2008 - Published in Atmos. Chem. Phys. Discuss.: 9 February 2009

Revised: 29 May 2009 - Accepted: 26 June 2009 - Published: 12 August 2009

\begin{abstract}
The factors that control the influence of deep convective detrainment on water vapor in the tropical upper troposphere are examined using observations from multiple satellites in conjunction with a trajectory model. Deep convection is confirmed to act primarily as a moisture source to the upper troposphere, modulated by the ambient relative humidity (RH). Convective detrainment provides strong moistening at low RH and offsets drying due to subsidence across a wide range of RH. Strong day-to-day moistening and drying takes place most frequently in relatively dry transition zones, where between $0.01 \%$ and $0.1 \%$ of Tropical Rainfall Measuring Mission Precipitation Radar observations indicate active convection. Many of these strong moistening events in the tropics can be directly attributed to detrainment from recent tropical convection, while others in the subtropics appear to be related to stratosphere-troposphere exchange. The temporal and spatial limits of the convective source are estimated to be about $36-48 \mathrm{~h}$ and $600-1500 \mathrm{~km}$, respectively, consistent with the lifetimes of detrainment cirrus clouds. Larger amounts of detrained ice are associated with enhanced upper tropospheric moistening in both absolute and relative terms. In particular, an increase in ice water content of approximately $400 \%$ corresponds to a $10-90 \%$ increase in the likelihood of moistening and a 30-50\% increase in the magnitude of moistening.
\end{abstract}

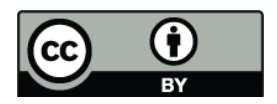

Correspondence to: J. S. Wright (jw2519@columbia.edu)

\section{Introduction}

Understanding the interactions of tropical deep convection and upper tropospheric humidity has proved to be a critically important step toward the development of more accurate climate models. Climate change due to the infrared water vapor feedback is acutely sensitive to changes in the upper tropospheric water vapor (UTWV) distribution in the tropics and subtropics (Shine and Sinha, 1991), yet this distribution remains a significant source of uncertainty in climate models (Soden and Held, 2006; Randall et al., 2007). Much of this uncertainty can be attributed to the relatively unknown factors governing moist convective outflow into the tropical upper troposphere.

To first order, the influence of convective detrainment on tropical UTWV is governed by the temperature at the location of detrainment, and current climate models typically parameterize it accordingly. The detrainment and advection of anvil ice may or may not lead to moistening away from the convective column. Detrained ice can persist in the form of cirrus clouds for up to two days and be advected over distances on the order of $1000 \mathrm{~km}$, and elevated water vapor anomalies are often even more persistent (Luo and Rossow, 2004). The overall impact of convection on UTWV is therefore also dependent on atmospheric conditions away from the location of detrainment. This effect is not adequately accounted for in most current climate models (Del Genio et al., 2005; Waliser et al., 2009).

The role of detrained ice in determining UTWV is likely to be strongly modulated by the ambient relative humidity with respect to ice $(\mathrm{RH})$. In this paper, $\mathrm{RH}$, humidity, and

Published by Copernicus Publications on behalf of the European Geosciences Union. 
humid always refer to relative humidity with respect to ice, while water vapor, $w$, and UTWV denote the absolute water vapor content. By ambient, we mean the surrounding environmental conditions prior to convective detrainment. Ice will sublimate and moisten the environment only when the ambient RH is below saturation; otherwise, vapor may condense or deposit onto existing hydrometeors and precipitate out of the local environment. This relationship implies that the influence of convective detrainment on the local vapor mixing ratio will be intrinsically dependent upon the local ambient RH. In particular, the introduction of ice into subsaturated environments through either convection or advection from convective towers may be a particularly efficient mechanism for moistening the upper troposphere. Convection is largely constrained to regions that are already humid (Sherwood, 1996), so the overall effect of ice advection and sublimation on UTWV is unclear.

The strength of the water vapor feedback to climate change is strongly influenced by water vapor changes in the subtropical upper troposphere (Sun and Lindzen, 1993; Pierrehumbert, 1995). Convection occurs primarily in the humid tropics, however, and air detrained from this convection is generally dehydrated as it is advected into the subtropics. The extent to which effective moistening occurs in the subtropical upper troposphere remains unresolved, as does the nature of the processes responsible for this moistening.

Current climate models are often poorly equipped to handle the evolution and microphysics of anvil clouds, preferring instead to detrain a fixed fraction of convective condensate (Del Genio et al., 2005). A more complete physical characterization of how convective detrainment interacts with upper tropospheric humidity may thus help to identify how model representations of the relationships between deep convective anvils and downstream UTWV can be most effectively improved. Recent advances in satellite remote sensing capabilities provide an unprecedented opportunity to examine this interaction.

The Tropical Rainfall Measuring Mission (TRMM) Precipitation Radar (PR) is the first precipitation radar instrument in space (Kummerow et al., 1998). While the instrument's primary purpose is to observe the three-dimensional structure and amount of rainfall, it can also be used to characterize the structure and properties of strong convection (radar reflectivity $Z \gtrsim 20 \mathrm{dBZ}$ ) throughout the tropics. To date, these observations have been most frequently applied to studies of the spatial and temporal distribution (e.g., Petersen and Rutledge, 2001), intrinsic properties (e.g., Nesbitt and Zipser, 2003), and climate response (e.g., Rapp et al., 2005) of convective clouds. In this paper, we expand upon this previous work by relating PR observations of tropical deep convection directly to downstream changes in UTWV.

Observations of deep convection serve as the initial conditions for a trajectory model, which is integrated forward in time for two days. Trajectory points are matched to nearby observations of $\mathrm{RH}$ and water vapor mixing ratio from the
Atmospheric Infrared Sounder (AIRS) (Aumann et al., 2003) whenever possible, both prior to and following trajectory passage. This allows us to characterize UTWV changes in the vicinity of convection as a function of both convective properties and ambient RH. The AIRS instrument provides profiles of both water vapor and temperature at high vertical resolution $(1-3 \mathrm{~km})$, so that information about the vertical structure of both convection and $\mathrm{RH}$ can be included in the analysis.

A number of previous studies have applied observational data to examine the relationships between tropical deep convection and upper tropospheric humidity (e.g., Soden and Fu, 1995; McCormack et al., 2000; Soden, 2004; Luo et al., 2007). These works have almost exclusively used cloud observations from geostationary satellites. Geostationary data offers better temporal and spatial coverage than the TRMM $\mathrm{PR}$, but contains neither the vertical structure nor the ice water content information that can be inferred from the PR. The AIRS water vapor observations also offer advantages over previous data sources, most notably the ability to perform retrievals for pixels with up to $70 \%$ cloud cover. In addition, the vertical sensitivity of the AIRS instrument suite allows us to better focus our analysis on the $300-200 \mathrm{hPa}$ layer, where deep convective detrainment is at a maximum ( $\mathrm{Fu}$ et al., 1994; Folkins et al., 2002).

Previous works have tended to focus on either a local (i.e., collocated cloud and water vapor) or Lagrangian (i.e., evolution of cloud and water vapor along a calculated path) view of the influence of convective clouds on UTWV. Our analysis takes an Eulerian approach instead; that is, we examine the evolution of UTWV in a set volume as air detrained from convection passes through it, much like the evolution of water vapor in a general circulation model (GCM) grid box. This approach enables us to develop statistics that can be more readily used to evaluate and constrain GCM parameterizations.

We describe the observational data and analysis method in more detail in Sect. 2. Results for the global tropics are presented in Sect. 3. Section 4 examines the geographical distribution and evolution of the relationships reported in Sect. 3, and Sect. 5 describes the relative roles of ice water content and detrainment height in determining these relationships. We examine our results within the context of previous work in Sect. 6, and discuss their potential as a valuable observational constraint for GCM representations of deep convective detrainment. The primary results of this paper are summarized in Sect. 7.

\section{Data and method}

\subsection{Observations of convective clouds}

Deep convection is identified using reflectivity observations provided by the Tropical Rainfall Measuring Mission 
(TRMM) precipitation radar (PR) (Kummerow et al., 1998). The TRMM PR operates at two frequencies straddling $13.8 \mathrm{GHz}(13.796 \mathrm{GHz}$ and $13.802 \mathrm{GHz})$, and scans a $215 \mathrm{~km}$ swath every $0.6 \mathrm{~s}$. We use the $2 \mathrm{~A} 25$ algorithm volumetric radar reflectivities, which indicate the amount of liquid or solid water contained in precipitation sized hydrometeors at a given location. These observations are provided on a vertical resolution of $250 \mathrm{~m}$ at nadir, increasing to about $1.6 \mathrm{~km}$ at the maximum inclination angle of $17^{\circ}$. The horizontal resolution of the footprint ranges from $4.3 \mathrm{~km}$ at nadir to $5 \mathrm{~km}$ at maximum inclination. Validation studies using high-resolution aircraft and ground-based radar measurements indicate that the TRMM PR performs well for systems with spatial scales comparable to or larger than the footprint (Heymsfield et al., 2000). We use only those observations that the data processing algorithm identifies as convective.

Radar reflectivity is a useful proxy of convective intensity; it is not, however, directly relevant to studies of climate. We therefore choose to convert TRMM PR observations from equivalent radar reflectivity factor $\left(Z_{e}\right.$, expressed in units of $\mathrm{mm}^{6} \mathrm{~m}^{-3}$ ) to ice water content (IWC, expressed in units of $\mathrm{g} \mathrm{m}^{-3}$ ). IWC is a fundamental property of clouds and has been shown to be important to the earth's radiation budget (e.g., Stephens and Greenwald, 1990). This conversion is performed using an empirical relationship derived from aircraft measurements in low-latitude convectively-generated anvil ice cloud layers (Heymsfield et al., 2006):

$\mathrm{IWC}=0.0778 Z_{e}^{0.513}$.

Particle size distributions (PSDs) observed during the Cirrus Regional Study of Tropical Anvils and Cirrus Layers - Florida Area Cirrus Experiment (CRYSTAL-FACE) were used in conjunction with direct measurements of IWC to develop mass-dimension relationships. These relationships were applied together with PSDs observed during CRYSTAL-FACE and the Convection and Moisture Experiment (CAMEX-4) aircraft field experiments to estimate the radar reflectivity that would be reported by TRMM (Heymsfield et al., 2004, 2006). The estimated reflectivities show good agreement with simultaneous satellite measurements of radar reflectivity near the in situ aircraft position. The uncertainty in IWC is estimated to be about a factor of two, based on applying a range of reasonable mass-dimension relationships. Protat et al. (2007) provide a detailed error analysis of similarly formulated IWC- $Z_{e}$ relationships for different radar frequencies $(35 \mathrm{GHz}$ and $95 \mathrm{GHz}$ ).

The properties of convection may vary greatly both regionally and seasonally; it is therefore problematic to apply one IWC- $Z_{e}$ relationship (formulated for vigorous tropical maritime convection) to convective clouds throughout the tropics. This limitation is unfortunately unavoidable at present, due to the low volume of in situ microphysical observations in the tropics. We have selected Eq. (1) both because it is constrained by in situ observations and because it includes an inference of the contribution of cloud ice (down to about $50 \mu \mathrm{m}$ ) in its overall estimate of IWC. This inclusion is important for this study because cloud ice sediments out of the upper troposphere more slowly, and is thus more likely to be advected away from the convective tower and affect downstream UTWV. Deierling et al. (2008) graphically analyzed ten other IWC- $Z_{e}$ relationships that account for nonprecipitating cloud ice, and Eq. (1) falls nearly in the middle of the range of estimated IWCs.

\subsection{Observations of water vapor}

Observations of water vapor mass mixing ratio are provided by the AIRS instrument suite onboard NASA's Aqua satellite (Aumann et al., 2003). These data represent the combined analysis of both infrared and microwave radiances, allowing the retrieval of temperature and water vapor profiles in up to $70 \%$ cloud cover (Susskind et al., 2003). Profiles are reported at 12 standard pressure levels between the surface and $100 \mathrm{hPa}$ with a vertical resolution of $1-3 \mathrm{~km}$ and a horizontal resolution of about $40 \mathrm{~km}$. We use version 4.0.9 of the data and require that both water vapor $\left(\mathrm{Qual} \_\mathrm{H}_{2} \mathrm{O}\right)$ and free troposphere temperature (Qual_Temp_Profile_Mid) quality flags indicate highest quality data (i.e., both the water vapor and temperature profiles are successfully retrieved and considered valid). Only observations of water vapor mass mixing ratio in excess of $6.2 \times 10^{-3} \mathrm{~g} \mathrm{~kg}^{-1}$ (the nominal detection threshold as reported by Gettelman et al., 2006) are included in our analysis.

Relative humidity with respect to ice (RH) is calculated for two layers $(300-250 \mathrm{hPa} ; 250-200 \mathrm{hPa})$ using the AIRS standard water vapor and support temperature products. A pressure-weighted mean temperature is derived for each layer assuming piecewise linearity in the support product temperature profile (5 levels ranging from $300 \mathrm{hPa}$ to $247.4 \mathrm{hPa}$ for the lower layer; 6 levels ranging from $260 \mathrm{hPa}$ to $190.3 \mathrm{hPa}$ for the upper), and the layer mean saturation vapor pressure with respect to ice $\left(e^{\#}\right)$ is estimated using a modified version of the Clausius-Clapeyron equation (Emanuel, 1994):

$\ln e^{\#}=23.33086-\frac{6111.72784}{T}+0.15215 \ln T$.

This equation is accurate to within $0.14 \%$ for $T$ between $193 \mathrm{~K}$ and $273 \mathrm{~K}$. Saturation vapor pressures are converted to mass mixing ratio prior to the calculation of RH. Gettelman et al. (2006) developed a climatology of AIRS RH using a similar approach, and found that the calculated $\mathrm{RH}$ product was not highly sensitive to the method of calculation.

Hagan et al. (2004) and Gettelman et al. (2004) have independently evaluated AIRS water vapor and temperature between $500 \mathrm{hPa}$ and $100 \mathrm{hPa}$ using Pre-Aura Validation Experiment aircraft measurements taken over Costa Rica and Houston, Texas. Both evaluations indicate that AIRS upper tropospheric water vapor profiles agree with aircraft 
data within $25 \%$ for measurements matched within one hour in time and $100 \mathrm{~km}$ in space. Gettelman et al. (2004) further concluded that AIRS temperature profiles in the tropical tropopause region agree with the aircraft observations to within $\pm 1.5 \mathrm{~K}$, and that relative humidity products derived from AIRS are reliable up to $200 \mathrm{hPa}$. Additional comparisons of version 4 data to dedicated radiosondes show RMS differences in the troposphere of within $\pm 1 \mathrm{~K}$ in $1 \mathrm{~km}$ layers for temperature and within $\pm 15 \%$ in $2 \mathrm{~km}$ layers for water vapor (Divakarla et al., 2006).

\subsection{Trajectory model}

We confine our study to the tropics $\left(15^{\circ} \mathrm{S}\right.$ to $\left.15^{\circ} \mathrm{N}\right)$, and define deep convection events as TRMM PR observations with altitudes above $10 \mathrm{~km}$ and radar reflectivities greater than $20 \mathrm{dBZ}$. The altitude threshold allows us to focus on the convective systems likely to most impact water vapor in the 300-200 hPa layer, where convective detrainment is maximum (Fu et al., 1994; Folkins et al., 2002). The reflectivity threshold is chosen to comfortably exceed the TRMM PR noise threshold $(\sim 17 \mathrm{dBZ})$.

The locations of TRMM PR observations meeting these criteria are used as inputs to the Goddard Fast Trajectory model (Schoeberl and Sparling, 1995) and integrated forward in space and time for five days. Horizontal motions are interpolated from United Kingdom Meteorological Office (UKMO) meteorological reanalyses (Swinbank and O'Neill, 1994). UKMO winds are updated daily at 12:00 UTC on a $2.5^{\circ}$ latitude $\times 3.75^{\circ}$ longitude grid. Diabatic motions along the trajectory are estimated from UKMO data via the radiative transfer scheme of Rosenfield et al. (1994). UKMO temperature is the primary input to the radiative transfer scheme, which incorporates a broadband parameterization of infrared heating and cooling as well as solar absorption. Absorption and emission by carbon dioxide, water vapor, and ozone are included. The trajectory integration is performed on a timestep of $1728 \mathrm{~s}(0.02 \mathrm{~d})$, and winds and heating rates are interpolated to the trajectory point at each timestep.

Each observed convective event initiates an ensemble of trajectories. The number of members in each ensemble is determined by the number of TRMM PR pixels meeting the criteria, so that broader and deeper convective events will tend to initialize a larger ensemble. The altitude and reflectivity criteria that we have chosen generate 3576273 trajectories between 1 January and 31 December of 2004. Only trajectories for January, April, July, and October (1 245 720) are included in this analysis.

\subsection{Analysis technique}

We then attempt to match each point along the trajectory between 300 and $200 \mathrm{hPa}$ to observations of water vapor mass mixing ratio and $\mathrm{RH}$ both before and after trajectory passage. The water vapor mixing ratio prior to trajectory passage and ambient RH are determined by averaging orbital AIRS observations over the previous $24 \mathrm{~h}$ within a $1^{\circ} \times 1^{\circ}$ gridbox centered on the trajectory position. Water vapor mixing ratio after trajectory passage is determined by an identical spatial matching mechanism, but the time window is shortened to only one hour to limit mixing time and better isolate the direct influence of convective detrainment, as well as for consistency with the existing AIRS validation in the upper troposphere (Hagan et al., 2004; Gettelman et al., 2004). The consistency between atmospheric temperature and humidity measured within the one hour interval as shown by these studies suggests that the changes from before to after trajectory passage are unlikely to be influenced by advection other than that represented by the trajectory. The time criterion for post-trajectory matching is the primary limiting factor on whether a given trajectory point can be used in this analysis. Successful matching was achieved for 1084885 trajectory points.

A normalized change in water vapor mixing ratio $(\langle\Delta w\rangle)$ is calculated by subtracting the "before" water vapor mixing ratio from the "after" water vapor mixing ratio and then dividing by the "before" value:

$\langle\Delta w\rangle=\frac{w_{\text {aft }}-w_{\text {bef }}}{w_{\text {bef }}}$

This normalization is performed to account for the steep drop in saturation mixing ratio across the $300-200 \mathrm{hPa}$ layer in the tropics (about a factor of 10). Without the normalization, changes in the 300-250 hPa portion of the analysis layer would dominate the distribution of $\Delta w$.

We present the results statistically. Empirical nonparametric probability density functions (PDFs) are estimated in two dimensions (Ambient RH and $\langle\Delta w\rangle$ ) by smoothing the dataset with a Gaussian kernel density estimator. Use of the Gaussian kernel implicitly assumes that the probability of a given point provides information about the probability of nearby points, which reduces the impact of random errors in both satellite measurements and trajectory position. The smoothing parameters for each kernel density estimator were calculated using SiZer software (Chaudhuri and Marron, 1999, available at http://www.wagner.com/ SiZer/SiZerDownload.html).

The results of the trajectory analysis are divided into several cases (see Table 1). The distribution of scenes linked to recent convection (LNK) includes all observations linked to convective detrainment by trajectory calculations. This distribution is then broken down according to season (JAN, APR, JUL, and OCT), continental (CONT) and maritime (MARI) convective types, time elapsed (TIM1-TIM4) and distance traveled (DST1-DST4) since detrainment, detrainment height (DET1-DET4), and ice water content derived from TRMM PR (IWC1-IWC4). Smoothing parameters for LNK are $3.1 \%$ for ambient $\mathrm{RH}, 0.13$ for $\langle\Delta w\rangle$, and $0.02 \mathrm{~g} \mathrm{~kg}^{-1}$ for $\Delta w$. Values for the other distributions are similar. 
Table 1. Abbreviations and descriptions for the twenty-eight presented distributions; the number of trajectory points meeting the matching criteria for each distribution; the fraction of strong decreases $\left(\mathcal{F}_{-l g} ;\langle\Delta w\rangle<-0.5\right)$ and strong increases $\left(\mathcal{F}_{+l g} ;\langle\Delta w\rangle>1\right)$ of water vapor; the threshold RH above which the likelihood of drying becomes greater than that of moistening; and the predicted mean water vapor mixing ratio change $(\overline{\Delta w})$ calculated from each distribution. $95 \%$ confidence intervals are specified for each quantity.

\begin{tabular}{|c|c|c|c|c|c|c|}
\hline Abbr. & Description & Number & $\mathcal{F}_{-l g}$ & $\mathcal{F}_{+l g}$ & Threshold & Predicted $\overline{\Delta w}$ \\
\hline LNK & Linked to convection & 1084885 & $(6.6 \pm 0.05) \%$ & $(10.4 \pm 0.06) \%$ & $(50.0 \pm 0.1) \% \mathrm{RH}$ & $+(0.012 \pm 0.0001) \mathrm{g} \mathrm{kg}^{-1}$ \\
\hline GRD & Background distribution & 4328076 & $(10.8 \pm 0.03) \%$ & $(9.4 \pm 0.03) \%$ & $(25.7 \pm 0.1) \% \mathrm{RH}$ & $-(0.001 \pm 0.0001) \mathrm{g} \mathrm{kg}^{-1}$ \\
\hline JAN & January LNK & 226028 & $(7.3 \pm 0.11) \%$ & $(9.8 \pm 0.12) \%$ & $(47.3 \pm 0.2) \% \mathrm{RH}$ & $+(0.010 \pm 0.0001) \mathrm{g} \mathrm{kg}^{-1}$ \\
\hline APR & April LNK & 296660 & $(7.6 \pm 0.10) \%$ & $(12.5 \pm 0.12) \%$ & $(47.5 \pm 0.3) \%$ RH & $+(0.014 \pm 0.0004) \mathrm{g} \mathrm{kg}^{-1}$ \\
\hline JUL & July LNK & 270934 & $(6.0 \pm 0.09) \%$ & $(9.7 \pm 0.11) \%$ & $(51.7 \pm 0.1) \%$ RH & $+(0.010 \pm 0.0006) \mathrm{g} \mathrm{kg}^{-1}$ \\
\hline OCT & October LNK & 291263 & $(5.6 \pm 0.08) \%$ & $(9.4 \pm 0.11) \%$ & $(53.7 \pm 0.5) \% \mathrm{RH}$ & $+(0.013 \pm 0.0006) \mathrm{g} \mathrm{kg}^{-1}$ \\
\hline CONT & Continental convection & 488865 & $(6.6 \pm 0.07) \%$ & $(10.9 \pm 0.09) \%$ & $(53.2 \pm 0.1) \% \mathrm{RH}$ & $+(0.013 \pm 0.0001) \mathrm{g} \mathrm{kg}^{-1}$ \\
\hline MARI & Maritime convection & 596020 & $(6.6 \pm 0.06) \%$ & $(10.0 \pm 0.08) \%$ & $(47.0 \pm 0.1) \% \mathrm{RH}$ & $+(0.011 \pm 0.0003) \mathrm{g} \mathrm{kg}^{-1}$ \\
\hline TIM1 & lag time 0 to $12 \mathrm{~h}$ & 306214 & $(3.2 \pm 0.06) \%$ & $(16.1 \pm 0.13) \%$ & $(61.0 \pm 0.1) \%$ RH & $+(0.033 \pm 0.0001) \mathrm{g} \mathrm{kg}^{-1}$ \\
\hline TIM2 & lag time 12 to $24 \mathrm{~h}$ & 431906 & $(7.6 \pm 0.08) \%$ & $(9.5 \pm 0.09) \%$ & $(50.0 \pm 0.1) \% \mathrm{RH}$ & $+(0.007 \pm 0.0004) \mathrm{g} \mathrm{kg}^{-1}$ \\
\hline TIM3 & lag time 24 to $36 \mathrm{~h}$ & 277938 & $(8.0 \pm 0.10) \%$ & $(6.8 \pm 0.09) \%$ & $(42.4 \pm 0.1) \% \mathrm{RH}$ & $+(0.001 \pm 0.0006) \mathrm{g} \mathrm{kg}^{-1}$ \\
\hline TIM4 & lag time 36 to $48 \mathrm{~h}$ & 68827 & $(9.9 \pm 0.22) \%$ & $(5.0 \pm 0.16) \%$ & $(33.4 \pm 0.2) \%$ RH & $-(0.009 \pm 0.0005) \mathrm{g} \mathrm{kg}^{-1}$ \\
\hline DST1 & distance 0 to $300 \mathrm{~km}$ & 378529 & $(5.7 \pm 0.07) \%$ & $(13.1 \pm 0.11) \%$ & $(55.3 \pm 0.1) \%$ RH & $+(0.022 \pm 0.0001) \mathrm{g} \mathrm{kg}^{-1}$ \\
\hline DST2 & distance 300 to $600 \mathrm{~km}$ & 316446 & $(6.8 \pm 0.09) \%$ & $(10.5 \pm 0.11) \%$ & $(48.4 \pm 0.1) \%$ RH & $+(0.010 \pm 0.0004) \mathrm{g} \mathrm{kg}^{-1}$ \\
\hline DST3 & distance 600 to $900 \mathrm{~km}$ & 183491 & $(8.1 \pm 0.12) \%$ & $(7.8 \pm 0.12) \%$ & $(45.9 \pm 0.1) \% \mathrm{RH}$ & $+(0.002 \pm 0.0006) \mathrm{g} \mathrm{kg}^{-1}$ \\
\hline DST4 & distance $\geq 900 \mathrm{~km}$ & 206377 & $(6.6 \pm 0.11) \%$ & $(7.6 \pm 0.11) \%$ & $(44.8 \pm 0.1) \% \mathrm{RH}$ & $+(0.004 \pm 0.0006) \mathrm{g} \mathrm{kg}^{-1}$ \\
\hline DET1 & $\theta_{\mathrm{det}}<340 \mathrm{~K}$ & 22438 & $(5.8 \pm 0.31) \%$ & $(18.2 \pm 0.50) \%$ & $(54.6 \pm 0.1) \% \mathrm{RH}$ & $+(0.029 \pm 0.0002) \mathrm{g} \mathrm{kg}^{-1}$ \\
\hline DET2 & $\theta_{\text {det }} 340$ to $344 \mathrm{~K}$ & 488022 & $(6.8 \pm 0.07) \%$ & $(11.1 \pm 0.09) \%$ & $(51.4 \pm 0.1) \% \mathrm{RH}$ & $+(0.015 \pm 0.0004) \mathrm{g} \mathrm{kg}^{-1}$ \\
\hline DET3 & $\theta_{\text {det }} 344$ to $348 \mathrm{~K}$ & 523491 & $(6.5 \pm 0.07) \%$ & $(9.2 \pm 0.08) \%$ & $(49.0 \pm 0.1) \% \mathrm{RH}$ & $+(0.008 \pm 0.0005) \mathrm{g} \mathrm{kg}^{-1}$ \\
\hline DET4 & $\theta_{\mathrm{det}} \geq 348 \mathrm{~K}$ & 50934 & $(5.7 \pm 0.20) \%$ & $(11.8 \pm 0.28) \%$ & $(47.6 \pm 0.5) \% \mathrm{RH}$ & $+(0.009 \pm 0.0005) \mathrm{g} \mathrm{kg}^{-1}$ \\
\hline IWC1 & IWC 0.8 to $2 \mathrm{~g} \mathrm{~m}^{-3}$ & 884977 & $(6.7 \pm 0.05) \%$ & $(10.2 \pm 0.06) \%$ & $(49.3 \pm 0.1) \%$ RH & $+(0.011 \pm 0.0001) \mathrm{g} \mathrm{kg}^{-1}$ \\
\hline IWC2 & IWC 2 to $3 \mathrm{~g} \mathrm{~m}^{-3}$ & 123807 & $(6.5 \pm 0.14) \%$ & $(10.5 \pm 0.17) \%$ & $(52.2 \pm 0.2) \% \mathrm{RH}$ & $+(0.012 \pm 0.0004) \mathrm{g} \mathrm{kg}^{-1}$ \\
\hline IWC3 & IWC 3 to $4 \mathrm{~g} \mathrm{~m}^{-3}$ & 40414 & $(5.9 \pm 0.23) \%$ & $(11.1 \pm 0.31) \%$ & $(54.0 \pm 0.3) \% \mathrm{RH}$ & $+(0.015 \pm 0.0006) \mathrm{g} \mathrm{kg}^{-1}$ \\
\hline IWC4 & $\mathrm{IWC} \geq 4 \mathrm{~g} \mathrm{~m}^{-3}$ & 35687 & $(5.9 \pm 0.24) \%$ & $(12.6 \pm 0.34) \%$ & $(56.7 \pm 0.3) \%$ RH & $+(0.019 \pm 0.0007) \mathrm{g} \mathrm{kg}^{-1}$ \\
\hline
\end{tabular}

To provide context, a background distribution (GRD in Table 1) is calculated by aggregating AIRS RH and water vapor mixing ratio into $1^{\circ} \times 1^{\circ}$ bins and computing the daily means. We then identify every grid box in the tropics $\left(15^{\circ} \mathrm{S}-15^{\circ} \mathrm{N}\right)$ for which we have data on successive days. The ambient RH is considered to be the mean $\mathrm{RH}$ on the first day, and $\langle\Delta w\rangle$ is the relative change in water vapor mixing ratio between day 1 $\left(w_{\text {bef }}\right)$ and day $2\left(w_{\text {aft }}\right)$, calculated according to Eq. (3). The LNK distribution is essentially a subset of the GRD distribution, although the cases that comprise LNK are not explicitly included in the calculation of GRD due to its different aggregation method (i.e., no trajectories are used in the calculation of GRD).

\section{Global tropics and seasonal cycle}

In this section, we present features of the relationship between ambient RH and local water vapor changes in the global tropics. Previous studies have established that the extent of moistening or drying is dependent on ambient RH; however, the probability distribution of this dependence has not been characterized observationally. Figure 1 shows empirical non-parametric PDFs of normalized water vapor mixing ratio difference $(\langle\Delta w\rangle)$ and ambient $\mathrm{RH}$ for scenes linked to convective detrainment (LNK) and for all scenes, regardless of whether they have been linked to convection (GRD). $\mathrm{RH}$ is binned into intervals of $6 \%$ and $\langle\Delta w\rangle$ is binned into intervals of 0.2 . To illustrate the interpretation of the twodimensional PDFs, we first identify several well-known features of the tropical upper tropospheric hydrologic cycle.

The LNK distribution is shifted rightward in each $\langle\Delta w\rangle$ bin and upward in each RH bin relative to the GRD distribution. The rightward shift indicates that the observed convection occurs primarily in environments that are already humid, while the upward shift shows that convection acts as a net moisture source. Both of these results are qualitatively consistent with previous work (e.g., Soden and Fu, 1995; Sherwood, 1996). Our results suggest that the direct influence of tropical deep convection is mostly limited to regions where the ambient RH is greater than about $25 \%$. As the ambient RH decreases, however, convection becomes progressively more efficient at moistening the environment. We will 
(a) LNK

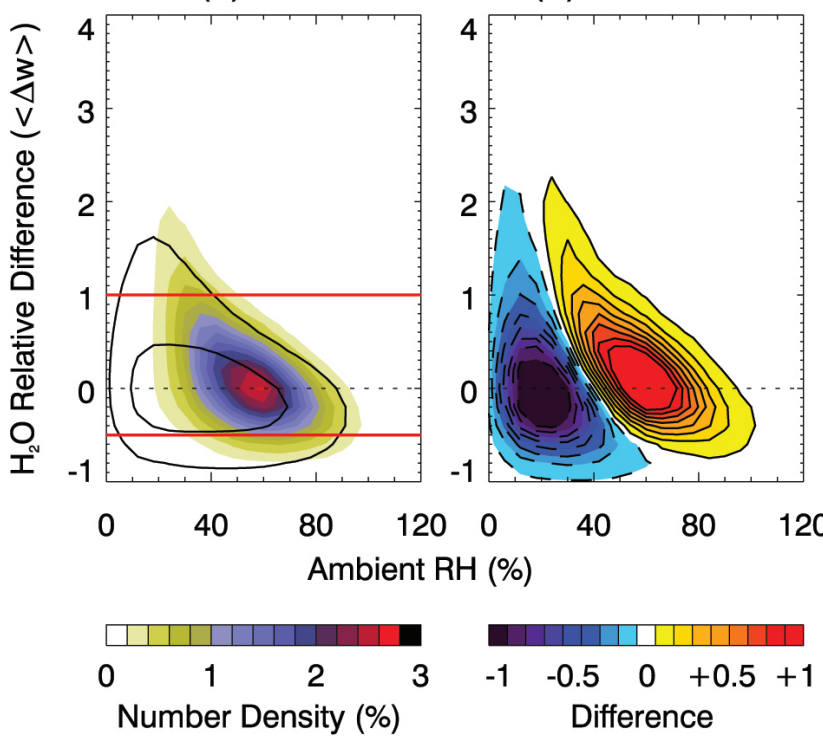

Fig. 1. (a) Empirical parametric probability distribution of relative change in water vapor mixing ratio $(\langle\Delta w\rangle)$ according to initial ambient relative humidity with respect to ice $(\mathrm{RH})$, averaged over all months considered. Filled contours represent observations that are linked to TRMM convective events within the previous $48 \mathrm{~h}$ (LNK); black contours represent daily mean AIRS observations regardless of whether they are linked to convection (GRD). Contours for the GRD distribution are plotted at $0.2,1,2$, and $3 \%$, so that they match up with the color transitions in the LNK distribution. (b) Difference between the LNK and GRD distributions. Contour intervals are identical to color scale; dashed contours represent negative values. Shading indicates statistical significance at $95 \%$ using the Kolmogorov-Smirnov test.

examine the extent to which detrained ice contributes to this enhanced efficiency in Sect. 5.

Moistening in the upper troposphere is generally effected by strong but infrequent events related to convection, and is largely balanced by the weaker but more sustained drying influence of large-scale subsidence. This competition is apparent in Fig. 1b. Even when the LNK distribution predicts mostly drying, convective detrainment still acts to offset the more drastic drying predicted by the GRD distribution.

Large changes in UTWV are especially interesting, as these changes will alter local radiative heating rates most dramatically. In this analysis, we define large changes as increases to more than double $(\langle\Delta w\rangle>1)$ and decreases to less than half $(\langle\Delta w\rangle<-0.5)$ the previous value (shown as red horizontal lines in Fig. 1a). The prevalence of these strong changes is reversed between the LNK and GRD distributions; strong moistening is more common for scenes linked to convection, while gridded scenes are more likely to experience strong drying (see columns 3 and 4 of Table 1). The occurrences of strong drying and strong moistening are more balanced in the GRD distribution than the LNK distribution. This balance reflects the inclusion of scenes both affected and unaffected by recent convection in GRD. Strong increases in $\langle\Delta w\rangle$ are observed at low $\mathrm{RH}$ in the GRD distribution much more frequently than in the LNK distribution. While it is possible that some of these strong moistening events are directly linked to convection, very few such cases are observed in the LNK distribution. It is much more likely that they are the result of large-scale mixing between moist and dry air masses.

Formulating the ambient $\mathrm{RH}-\Delta w$ relationship in terms of empirical PDFs allows us to predict a mean water vapor mixing ratio change $(\overline{\Delta w})$ for each distribution:

$\overline{\Delta w}=\sum_{j}\left[\Delta w_{j} \sum_{i} \operatorname{Pr}\left(\mathrm{RH}_{i}, \Delta w_{j}\right)\right]$,

where $\mathrm{RH}_{i}$ and $\Delta w_{j}$ are the center values of the $\mathrm{RH}$ and $\Delta w$ bins, respectively, and $\operatorname{Pr}$ is the two-dimensional probability function. In this case, $\Delta w$ is not normalized by $w_{\text {bef }}$, but is calculated explicitly as $w_{\text {aft }}-w_{\text {bef }}$ and expressed in $\mathrm{g} \mathrm{kg}^{-1}$. We expect $\overline{\Delta w}$ to be nearly zero for the GRD distribution, and find its value to be $(-0.001 \pm 0.0001) \mathrm{g} \mathrm{kg}^{-1}$. An observational bias toward clear skies in the AIRS data may account for $\overline{\Delta w}$ being slightly negative. Water vapor retrievals are less likely to be of high quality for cloudy fields of view, where upward motion and convective-related moistening is most likely to take place. Clear sky fields of view are often dominated by subsidence, and will thus typically undergo drying. Since we are tracking day-to-day changes, our method contains a slight preference for grid locations that are predominantly clear sky on both days. This preference introduces a bias toward locations that are predominantly undergoing drying.

The frequency of moistening $\left(\mathcal{F}_{+}\right.$, defined as the likelihood of positive $\langle\Delta w\rangle$ in a given $\mathrm{RH}$ bin) for the LNK and GRD distributions is shown in Fig. 2. The RH threshold below which moistening becomes more common than drying in the LNK distribution is $(50 \pm 0.1) \% \mathrm{RH}$. This threshold is reduced to $(25.7 \pm 0.1) \% \mathrm{RH}$ in the GRD distribution. This reduction is expected because, in the absence of convective detrainment, the likelihood of mixing with a more humid air mass is only significant when the local RH is substantially below the mean upper tropospheric RH.

$\mathcal{F}_{+}$for the LNK case exceeds that for the GRD case up to about $90 \% \mathrm{RH}$. At higher relative humidities, $\mathcal{F}_{+}$is greater for the GRD case than the LNK case. This reversal is significant at the $95 \%$ confidence level for RH greater than $95 \%$, and suggests that some aspect of convection acts to suppress the persistence of supersaturation. In other words, convective detrainment generally adds water vapor to subsaturated air and removes it from supersaturated air, so that the overall tendency is to pull the local RH toward saturation. Several mechanisms may be responsible for the suppression of supersaturation. These include downward motion that occurs 


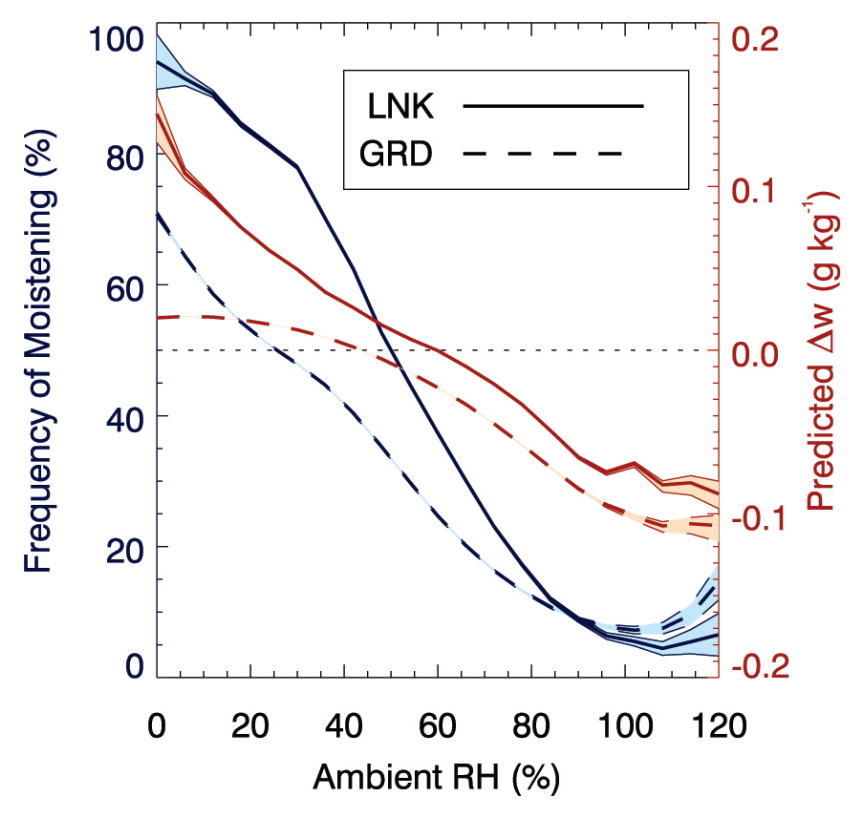

Fig. 2. Fraction of scenes that moisten $\left(\mathcal{F}_{+}=\operatorname{Pr}(\langle\Delta w\rangle>0)\right.$; blue lines and left ordinate) and predicted water vapor mixing ratio change ( $\overline{\Delta w}$; red lines and right ordinate) according to initial ambient RH. These diagnostics are shown both for observations linked to convection (LNK; solid lines) and gridded observations (GRD; dotted lines). Shading and bracketing lines indicate the 95\% confidence interval.

during anvil decay and the introduction of ice hydrometeors that can serve as sinks for the excess water vapor.

Although it is rare for convection to directly influence regions with low ambient RH (less than $10 \%$ of LNK cases have ambient $\mathrm{RH} \leq 25 \%$ ), it is very effective at moistening these environments when such conditions occur. According to the LNK distribution, $\mathcal{F}_{+}$for the bin $0<\mathrm{RH} \leq 24 \%$ is over $80 \%$. When the upper limit for this bin is raised to $48 \% \mathrm{RH}$, the calculated $\mathcal{F}_{+}$remains quite high, at nearly $70 \%$.

Figure 2 also shows the predicted water vapor mixing ratio change $\left(\overline{\Delta w_{i}}\right)$ for each RH bin. This quantity is calculated as in Eq. (4), excluding the summation over $i$. For all RH bins, the predicted $\overline{\Delta w_{i}}$ of the LNK distribution exceeds that of the GRD distribution. Moreover, as RH decreases, $\overline{\Delta w_{i}}$ increases much faster for LNK than GRD. Although largescale mixing of ambient air is capable of effecting large relative water vapor increases in dry locations (cf. Fig. 1), its absolute contribution to water vapor mixing ratio appears to be effectively capped. This is not true for mixing of air recently detrained from convection; in this case, the amount of added water vapor increases rapidly as RH decreases.

The seasonal cycle of the LNK distribution is shown in Fig. 3. The distributions appear to be grouped more by a sixmonth than a three-month cycle; the January and April distributions are similar, and the July and October distributions are similar. Generally, the seasonal maximum sea surface temperature lags the seasonal maximum land surface temperature by three months. Thus, the Northern Hemisphere surface temperature peaks in July over land and September over ocean. Combining land and ocean, convection peaks between July and September in the Northern Hemisphere, and between January and March in the Southern Hemisphere. The similarities in the July and October distributions and the January and April distributions may be a result of these seasonal hemispheric shifts in convective activity.

The July and October distributions are shifted toward higher ambient RH values, implying that deep convection is confined even more tightly to humid locations during the Northern Hemisphere summer months. In addition, deep convective detrainment tends to moisten humid locations more frequently during July and October. The seasonal cycle of TRMM PR observations during 2004 (not shown) indicates that July and October are characterized by stronger, deeper tropical convection than January and April, particularly over the continents. Stronger and deeper convection is also likely to increase the amplitude of convectively generated gravity waves (Lane et al., 2001), thus enhancing local wave-induced mixing in convective areas. Temperature fluctuations due to enhanced wave activity could in turn increase the likelihood of moistening locations that are already humid, especially since more vigorous convection is likely to supply additional ice water content to the upper troposphere.

\section{Geographic distribution and evolution}

In this section, we examine how water vapor changes and convection are spatially distributed in the global tropics. In particular, we discuss the influence of convective frequency on the magnitude of water vapor changes, and explore differences between continental and maritime convective regimes. We also examine the temporal and spatial evolution of mixing between ambient air and convectively detrained air.

The annual mean AIRS RH for the $300 \mathrm{hPa}$ to $200 \mathrm{hPa}$ layer in the tropics $\left(15^{\circ} \mathrm{S}-15^{\circ} \mathrm{N}\right)$ is shown in Fig. 4a, along with the frequency of deep convection (FDC) observed by TRMM PR. FDC is calculated on a $5^{\circ} \times 5^{\circ}$ grid as the number of convecting pixels ( $N_{\text {conv }}$ ) at $10 \mathrm{~km}$ divided by the total number of successfully observed (good quality) pixels $\left(N_{\text {obs }}\right)$. The RH maxima are collocated geographically with the maxima of deep convective activity. This relationship has been previously reported (e.g., Soden and Fu, 1995).

Figure $4 \mathrm{~b}$ shows the geographical distribution of the frequency of large moistening $\left(\mathcal{F}_{+l g} ;\langle\Delta w\rangle>1\right)$. This is calculated for each $5^{\circ} \times 5^{\circ}$ gridbox as the fraction of observed $\langle\Delta w\rangle$ values in the GRD distribution that are greater than 1 . The highest $\mathcal{F}_{+l g}$ ratios are located near the edges of maximum FDC, where the observed annual mean RH is generally between $25 \%$ and $50 \%$. The distribution of large decreases $\left(\mathcal{F}_{-l g}\right.$; white contours in Fig. $\left.4 \mathrm{~b}\right)$ is very similar, suggesting that these maxima occur where the variability of UTWV 


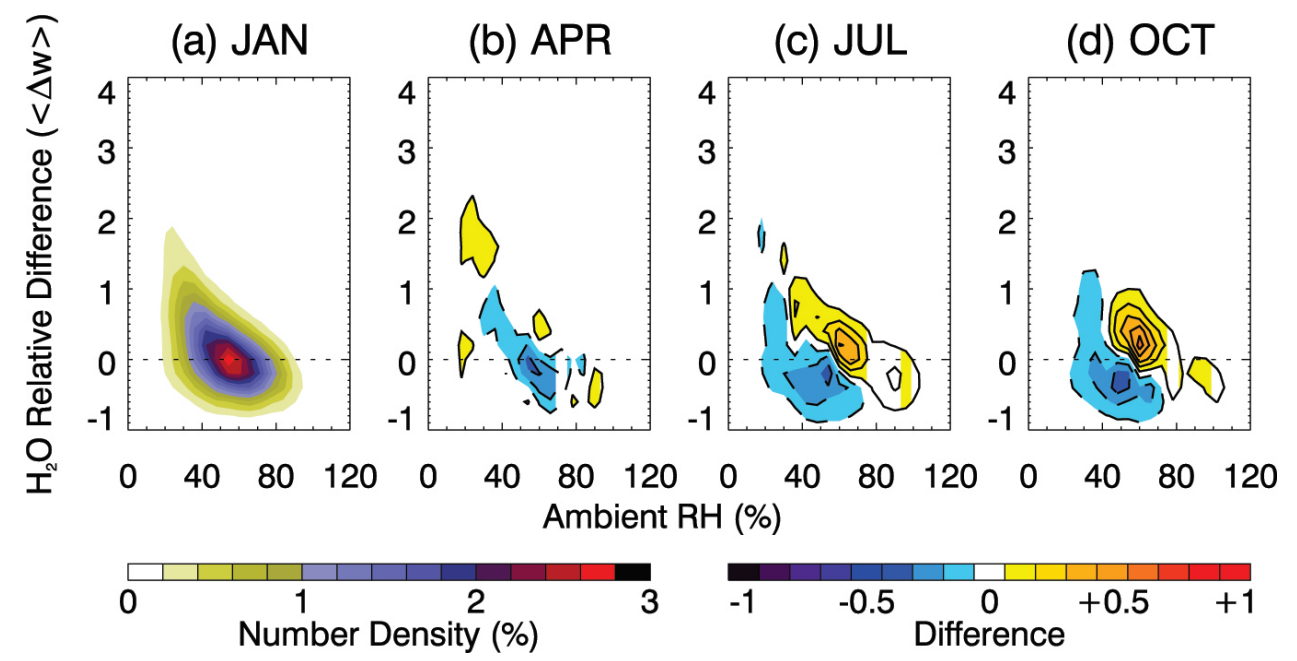

Fig. 3. (a) As in Fig. 1a, but for January 2004 (JAN). (b) As in Fig. 1b but for the difference between the APR (April 2004) and JAN distributions. (c) As in panel (b) but for the JUL (July 2004) and JAN distributions. (d) As in panel (b) but for the OCT (October 2004) and JAN distributions.

is highest. Maxima in the standard deviation of AIRS water vapor mixing ratio during the analysis period (not shown) are generally collocated with the maxima in both $\mathcal{F}_{+l g}$ and $\mathcal{F}_{-l g}$, further supporting this interpretation.

The grid locations where $\mathcal{F}_{+l g}$ is maximum correspond well to grid locations with intermediate FDC (Fig. 4a); i.e., between $.01 \%$ and $.1 \%$ of local TRMM PR observations indicate active deep convection at $10 \mathrm{~km}$. This agreement is particularly strong in the deep tropics. Regions of frequent deep convection have low to moderate $\mathcal{F}_{+l g}$, presumably because of consistently high $\mathrm{RH}$, and regions where convection rarely occurs tend to have low $\mathcal{F}_{+l g}$, presumably due to the lack of convective activity. This relationship breaks down in the subtropics. Many subtropical locations experience infrequent convection but exhibit high $\mathcal{F}_{+l g}$, such as near $\left(160^{\circ} \mathrm{W}\right.$, $15^{\circ} \mathrm{N}$ ). Most of these regions have been identified as centers of heightened tropopause fold activity and stratospheretroposphere exchange (Waugh and Polvani, 2000; Sprenger et al., 2003). Such activity has been shown to be associated with large changes in subtropical upper tropospheric water vapor (Waugh, 2005; Ryoo et al., 2008). UKMO horizontal winds at $250 \mathrm{hPa}$ (Fig. 4b) and the seasonal cycle of GRD $\mathcal{F}_{+l g}$ (not shown) both support this hypothesis. The Northern Hemisphere (Southern Hemisphere) $\mathcal{F}_{+l g}$ maxima are deepest in boreal (austral) winter, when the subtropical westerly jet is shifted closest to $15^{\circ} \mathrm{N}(\mathrm{S})$ and tropopause fold activity in the northern (southern) subtropics is most vigorous (Sprenger et al., 2003). The subtropical maxima in both $\mathcal{F}_{+l g}$ and $\mathcal{F}_{- \text {lg }}$ occur in nearly the same locations; this collocation is consistent with expectations for points that fluctuate between stratosphere and troposphere.
Figure $4 \mathrm{c}$ shows the geographical distribution of $\mathcal{F}_{+l g}$ based on the observations that comprise the LNK distribution, along with the density of trajectory points in each grid box. These two quantities combined indicate the extent to which the maxima in Fig. 4b are likely related to tropical convection. Some maxima are observed in both Fig. 4b and c, suggesting that recent tropical convection influences water vapor variability in these regions. These locations include the central tropical Pacific, the west coast of Africa near Guinea, the east coast of Africa near Madagascar, and the Coral Sea. Many of the subtropical maxima observed in Fig. 4b, such as those located near $\left(160^{\circ} \mathrm{W}, 15^{\circ} \mathrm{N}\right)$ and $\left(60^{\circ} \mathrm{W}, 20^{\circ} \mathrm{S}\right)$ do not appear in Fig. 4c. This supports our contention above that the large changes observed in those locations in Fig. 4b are likely related to stratosphere-troposphere exchange rather than recent tropical convection.

Just as maxima in FDC are generally collocated with low GRD $\mathcal{F}_{+l g}$, maxima in trajectory density are generally associated with low LNK $\mathcal{F}_{+l g}$ in Fig. 4c (e.g., tropical South America and the maritime continent). Equatorial Africa, however, exhibits high values of both trajectory density and $\mathcal{F}_{+l g}$ in Fig. 4c, without an associated maxima in Fig. 4b. This maximum in LNK $\mathcal{F}_{+l g}$ is strongest in April (the spring rainy season), moderate in October (the autumn rainy season), and relatively weak in January and July (dry seasons). Some echo of this signal appears in the seasonal cycle of GRD $\mathcal{F}_{+l g}$, but it is weaker than expected based on the combined trajectory density and $\mathcal{F}_{+l g}$. Such a mismatch might occur if strong moistening events due to convection do not typically persist. The value of $w_{\text {aft }}$ used to calculate LNK $\langle\Delta w\rangle$ is within one hour of trajectory passage. If this elevated water vapor mixing ratio does not persist until the next day, it will be unlikely to be observed in GRD $\mathcal{F}_{+l g}$. Other 
(a) AIRS Mean Relative Humidity

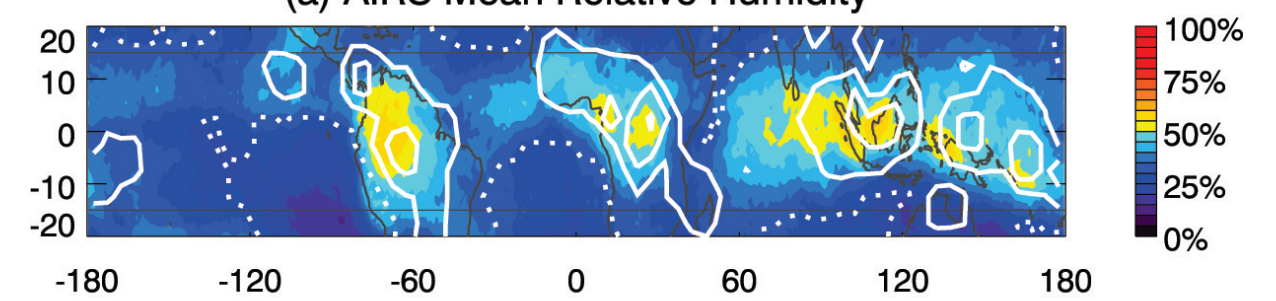

(b) Fraction of Large Positive $<\Delta w>$ (GRD)

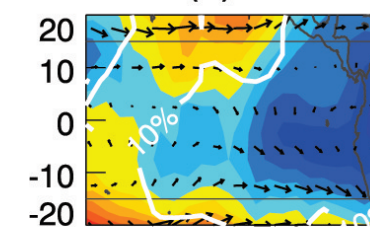

$-120$

$-60$
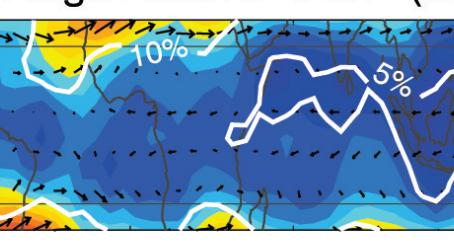

$-180$

(c) Fraction of Large Positive $<\Delta \mathrm{w}\rangle$ (LNK)
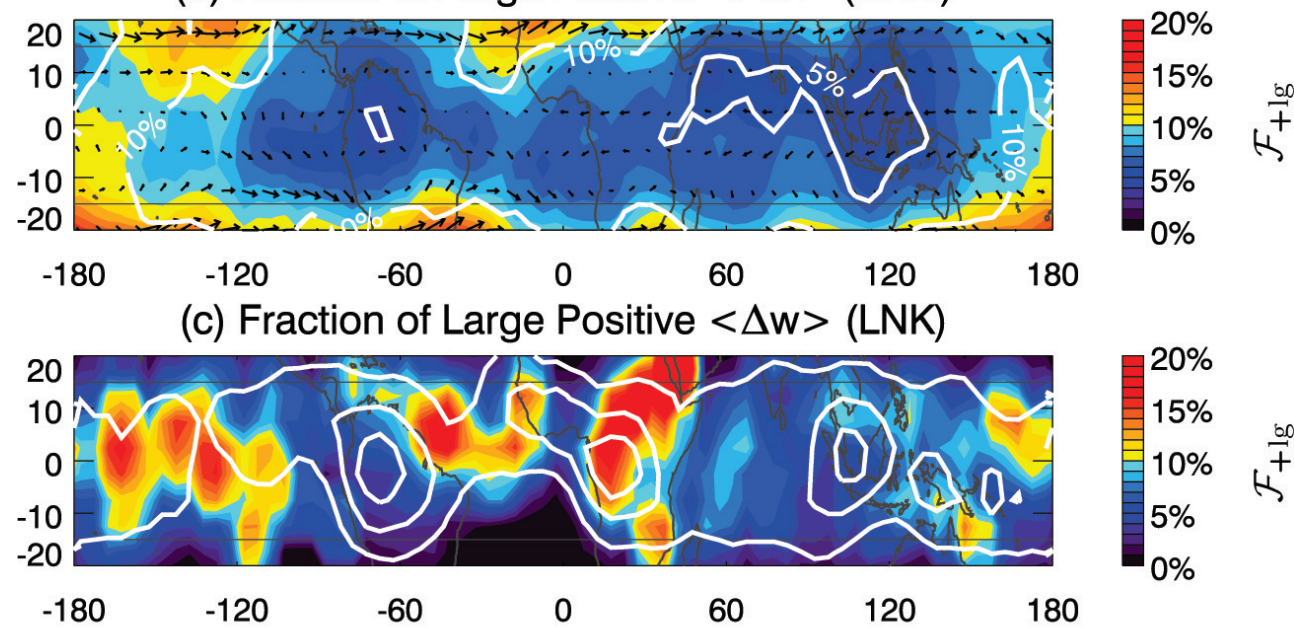

180
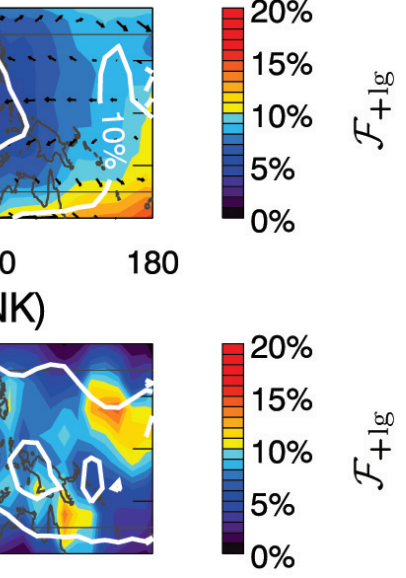

(d) Difference in Mean $\triangle \mathrm{w}$ (LNK-GRD)
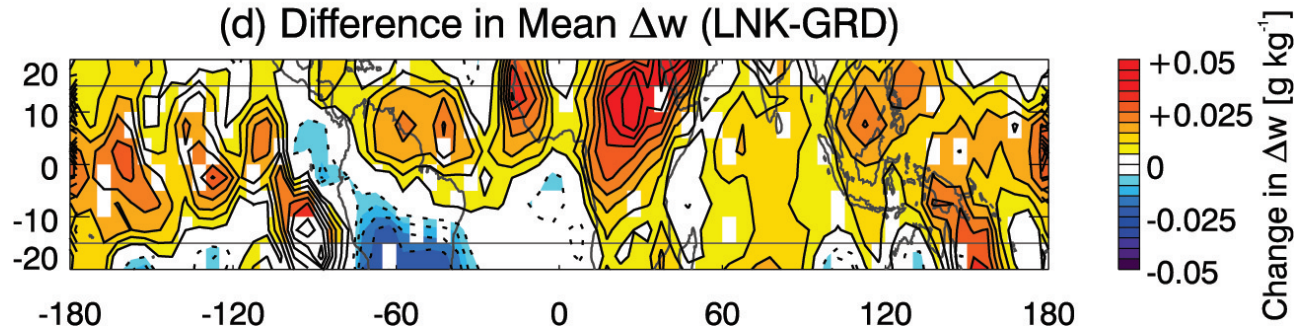

Fig. 4. (a) AIRS RH for the 300-200 hPa layer, overplotted with the frequency of deep convection (FDC) observed by TRMM PR at $10 \mathrm{~km}$ (white contours; dashed contour represents $.01 \%$, solid contours represent $0.1 \%, 0.2 \%$, and $0.3 \%$ ). (b) The observed fraction of large increases $\left(\mathcal{F}_{+l g}\right.$; filled contours) and large decreases $\left(\mathcal{F}_{-l g}\right.$; white contours) in AIRS water vapor mixing ratio for the GRD distribution. $\mathcal{F}_{-l g}$ contours are plotted at 5\%,10\%, and 15\%. Arrows show direction and relative magnitude of UKMO wind at $250 \mathrm{hPa}$. (c) As in panel (b) but for the LNK distribution, overplotted with trajectory density at $0.1 \%, 0.3 \%$, and $0.5 \%$. (d) Difference in mean water vapor mixing ratio change between the LNK and GRD distributions. Shading denotes statistical significance at the 95\% level using the t-means test. All quantities are means for the combined months of January, April, July, and October 2004 (123 days).

maxima in LNK $\mathcal{F}_{+l g}$, such as the eastern tropical Pacific and Persian Gulf, are located in regions that convective detrainment rarely influences (i.e., trajectory densities are less than $0.1 \%)$. Although Fig. $4 \mathrm{c}$ indicates that convection moistens this region very effectively, the low trajectory densities counteract this efficiency and effectively decouple the GRD $\mathcal{F}_{+l g}$ from its LNK counterpart.

Figure $4 \mathrm{~d}$ shows the difference in mean water vapor mixing ratio change between the LNK and GRD distributions. This difference is generally positive, consistent with our interpretation of convection as a moisture source based on Figs. 1 and 2. Areas where the difference is negative are fre- quently collocated with areas where GRD $\mathcal{F}_{+l g}$ is high and LNK $\mathcal{F}_{+l g}$ is low (Fig. $4 \mathrm{~b}-\mathrm{c}$ ). The majority of these locations are well-correlated with the subtropical jet (Fig. 4b). Not only does detrainment from tropical convection rarely effect large changes in the subtropics, it does not appear to contribute much water vapor at all beyond a few isolated regions (such as off the west coast of northern Africa).

The only large tropical region that exhibits a negative difference in mean water vapor mixing ratio change is central South America. This negative difference is caused both by a large positive value of GRD $\Delta w$ and a large negative value of LNK $\Delta w$. About a third to half of convection in subtropical 
(a) CONT

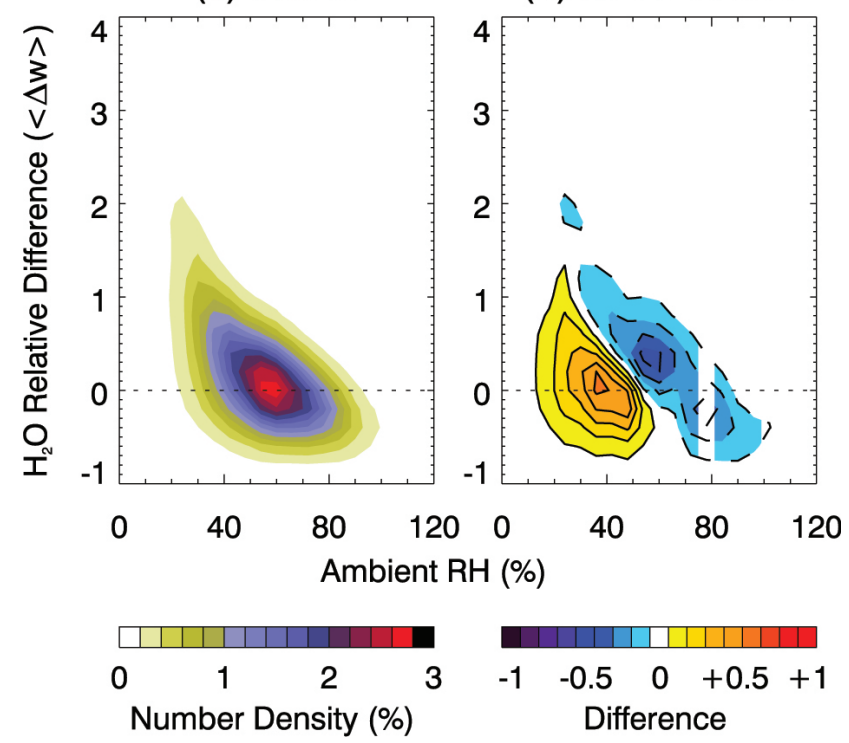

Fig. 5. (a) As in Fig. 1a, but for trajectories linked to continental convection (CONT). (b) As in Fig. 1b, but for the difference between the MARI (linked to maritime convection) and CONT distributions.

South America is associated with cold front incursions from the subtropics, peaking in austral winter (Garreaud and Wallace, 1998). Local moistening resulting from this convection could be swiftly and strongly offset by an influx of dry stratospheric air behind the cold fronts. This type of downward transport has been shown clearly for cold fronts over Europe (e.g., Wernli, 1997; Kentarchos et al., 1998), and the climatology of upper level cut-off lows over South America (Fuenzalida et al., 2005) is consistent with the seasonal cycle of the depth of the LNK-GRD difference.

The differences shown in Fig. $4 \mathrm{~d}$ are on the order of $0.01 \mathrm{~g} \mathrm{~kg}^{-1}$. The mean mixing ratio between $20^{\circ}$ and $20^{\circ}$ in the $300-200 \mathrm{hPa}$ layer observed by AIRS during this time period is $0.10 \mathrm{~g} \mathrm{~kg}^{-1}$, so the differences between LNK $\Delta w$ and GRD $\Delta w$ are on the order of $10 \%$ of the ambient water vapor amount.

We have broken the LNK distribution down into components linked to continental and maritime convection using the AIRS land/ocean mask. Figure 5 shows that continental convection is more likely to moisten the upper troposphere than maritime convection, even though it typically takes place in more humid environments. This difference is reflected in the diagnostics reported in Table 1. In particular, the CONT distribution exhibits a higher RH threshold for switching from moistening to drying, a greater $\mathcal{F}_{+l g}$, and a larger predicted $\overline{\Delta w}$.

Several factors may contribute to this dissimilarity. Continental convection is generally stronger and penetrates more deeply than its maritime counterpart (Petersen and Rutledge,
2001). Stronger updrafts carry larger quantities of ice, thus introducing additional water to the upper troposphere. In addition, continental environments tend to be more polluted, with greater supplies of cloud condensation nuclei. This may result in a greater proportion of cloud ice water content (IWC) being concentrated in smaller particles (Sherwood, 2002). Smaller particles will fall out of the upper troposphere more slowly, and are likely to moisten the upper troposphere more effectively (Sherwood, 2002; Del Genio et al., 2005). The differences between CONT and MARI persist, and in fact grow more pronounced, at longer lag times and larger distances from the convective source, particularly at low RH. This persistence is consistent with the first explanation, and the enhancement of the difference with time and distance is consistent with the second. The ice amount effect will be examined further in Sect. 5; the ice particle size effect is left here for future work.

Figure 6 shows the evolution of the LNK distribution with time elapsed since convection. Convective moistening occurs primarily during the first $12 \mathrm{~h}$ following convection. During this phase, $\mathcal{F}_{+l g}$ exceeds $16 \%$, the predicted $\overline{\Delta w}$ is greater than $0.3 \mathrm{~g} \mathrm{~kg}^{-1}$, and the RH threshold at which drying becomes more frequent than moistening is $(61 \pm 0.1) \%$. All of these diagnostics fall sharply at greater lag times, while $\mathcal{F}_{-l g}$ grows. The differences between the evolving distribution and the GRD distribution (not shown) gradually disappear at longer lag times. This is illustrated by the statistical descriptors reported in Table 1. $\mathcal{F}_{-l g}$ first exceeds $\mathcal{F}_{+l g}$ for the TIM3 distribution (24-36h), and the predicted $\overline{\Delta w}$ calculated from TIM4 (36-48 h) dips below even that calculated from GRD. Combining these metrics with a visual analysis of the PDF evolution, we estimate that the temporal limit of convective moistening is approximately $24-48 \mathrm{~h}$. This estimate agrees well with the lifetime of tropical detrainment cirrus reported by Luo and Rossow (2004) (19-30 $\pm 16 \mathrm{~h}$ ) and with the persistence of Lagrangian moisture anomalies downstream from convection reported by McCormack et al. (2000) $(\sim 30 \mathrm{~h})$.

Figure 7 shows how the LNK distribution evolves according to distance traveled since convective detrainment. As in Fig. 6, convective moistening is strongest close to the convective source, within $300 \mathrm{~km}$, and becomes generally weaker at progressively greater distances. This weakening is not as pronounced as that observed with elapsed time, however (cf. Table 1). Although comparison of time and distance evolution is necessarily first order, the time and distance bins have been chosen to correspond to an average windspeed of $9 \mathrm{~m} \mathrm{~s}^{-1}$, which agrees approximately with the mean UKMO windspeed between $20^{\circ} \mathrm{S}$ and $20^{\circ} \mathrm{N}$ at $250 \mathrm{hPa}\left(7.8 \mathrm{~m} \mathrm{~s}^{-1}\right)$. This suggests that time elapsed since detrainment exerts a stronger control on the moistening potential of detrained air than does distance traveled.

The distance limit of the convective source is more difficult to identify than the time limit, primarily because convective moistening weakens more slowly with the distance bins than with the time bins. We have calculated 


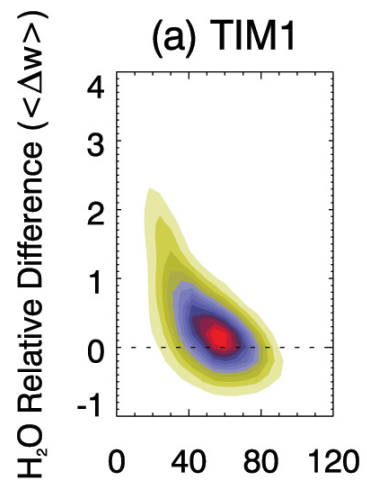

(b) TIM2-TIM1

(c) TIM3-TIM1

(d) TIM4-TIM1
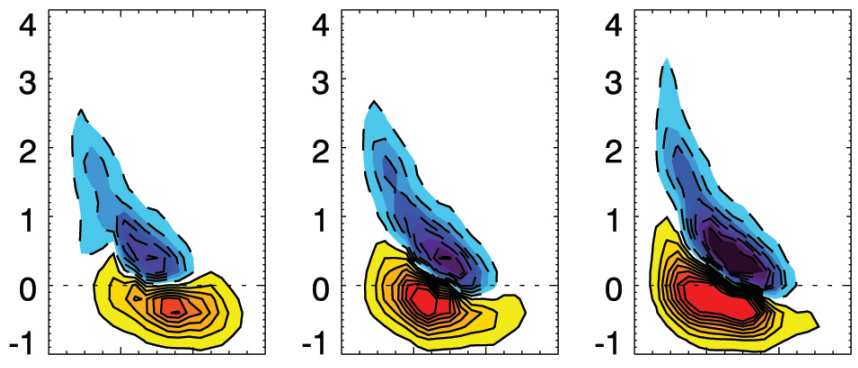

$40 \quad 80 \quad 120$

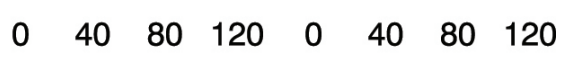

Ambient RH (\%)
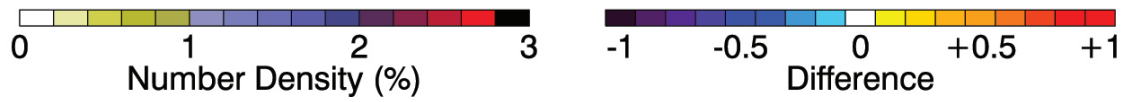

Fig. 6. (a) As in Fig. 1a, but for trajectory points with lag time since convection of $0-12 \mathrm{~h}$ (TIM1). (b) As in Fig. 1b, but for the difference between the TIM2 (lag times of 12-24h) and TIM1 distributions. (c) As in panel (b), but for the TIM3 (lag times of 24-36h) and TIM1 distributions. (d) As in panel (b) but for the TIM4 (lag times of 36-48 h) and TIM1 distributions.
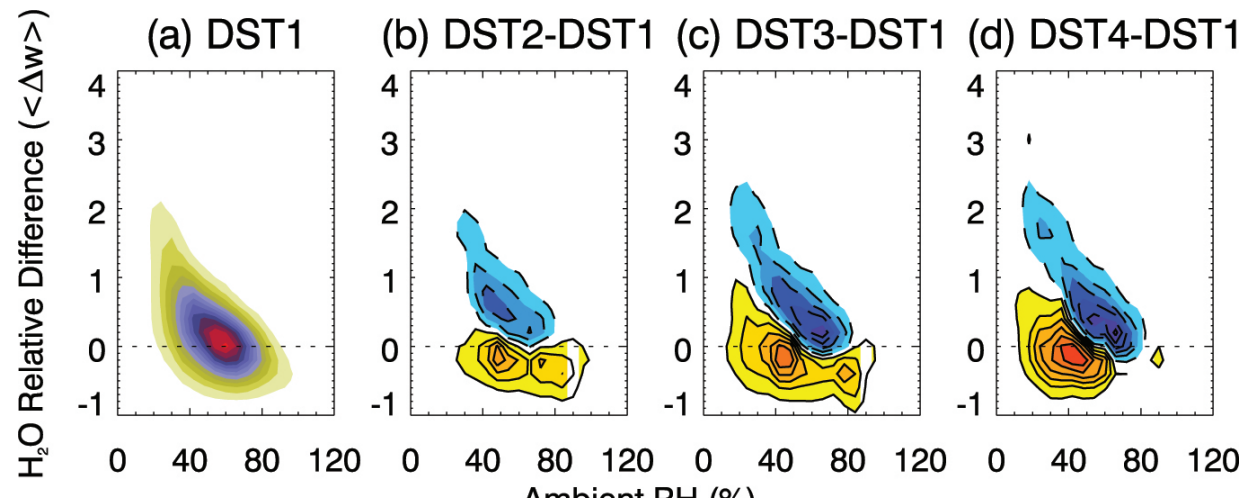

Ambient $\mathrm{RH}(\%)$
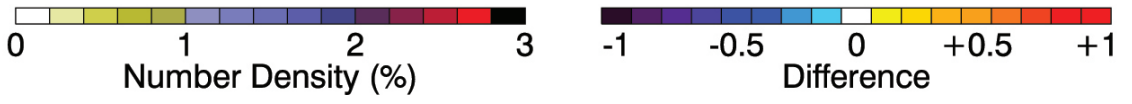

Fig. 7. (a) As in Fig. 1a, but for trajectory points with distance traveled since convection of 0-300 km (DST1). (b) As in Fig. 1b, but for the difference between the DST2 (travel distances of 300-600 km) and DST1 distributions. (c) As in panel (b) but for the DST3 (travel distances of 600-900 km) and DST1 distributions. (d) As in panel (b) but for the DST4 (travel distances greater than $900 \mathrm{~km}$ ) and DST1 distributions.

several additional distributions at progressively greater distances (not shown) to better identify the spatial limits of convective moistening. The lower and upper limits are identified similarly to above: $\mathcal{F}_{-l g}$ first exceeds $\mathcal{F}_{+l g}$ for the 600 $900 \mathrm{~km}$ bin (DST3), while the distribution is effectively static and identical to GRD beyond $1500 \mathrm{~km}$. The resulting estimate $(600-1500 \mathrm{~km})$ also corresponds well with the advection distances of tropical detrainment cirrus reported by Luo and Rossow (2004) (600-1000 km).

\section{The role of ice}

This section examines the role of ice amount in determining downstream water vapor changes. The results are contextualized by comparing them with the first order influence of detrainment temperature.

Figure 8 breaks the LNK distribution down into four detrainment potential temperature $\left(\theta_{\text {det }}\right)$ bins. Detrainment potential temperature is analogous to detrainment height, and is calculated from UKMO reanalysis data at the geometric altitude corresponding to the TRMM observation that initializes the trajectory. Convective moistening is more frequent 


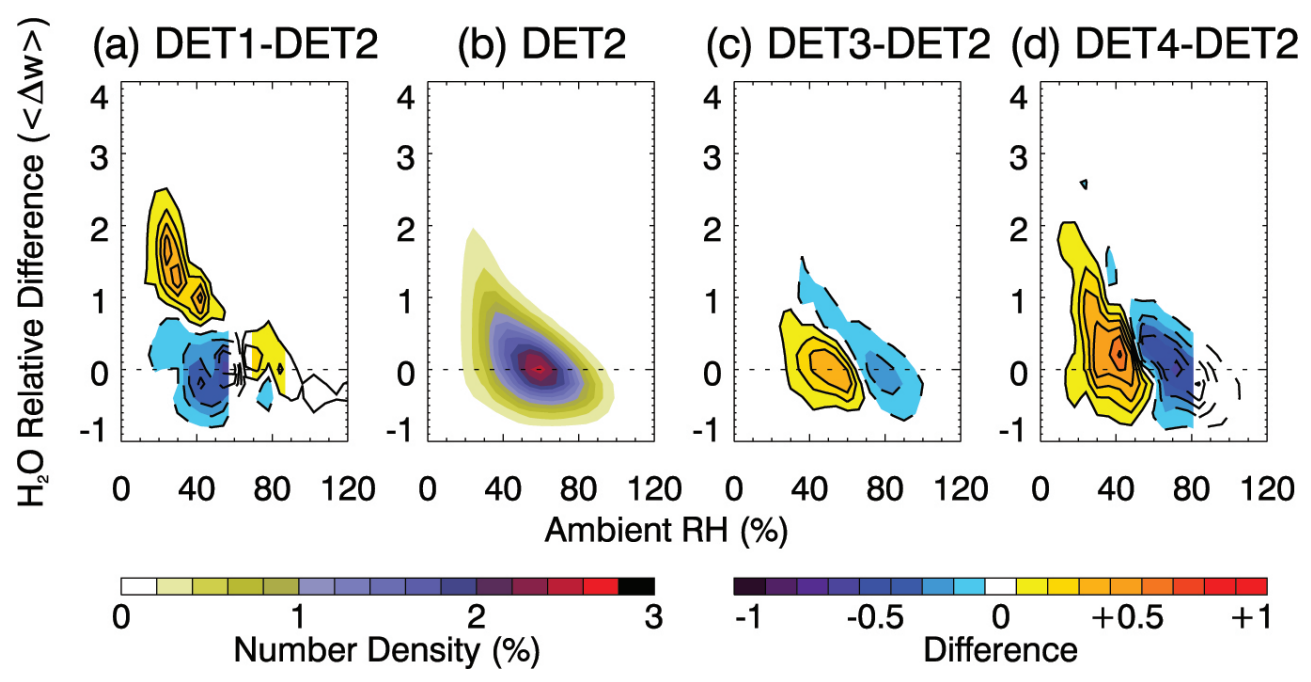

Fig. 8. (a) As in Fig. 1b, but for the difference between trajectories linked to detrainment potential temperatures $\left(\theta_{\text {det }}\right.$ less than $340 \mathrm{~K}$ (DET1) and trajectories linked to $\theta_{\text {det }}$ between 340 and $344 \mathrm{~K}$ (DET2). (b) As in Fig. 1a but for the DET2 distribution. (c) As in panel (a), but for the difference between the DET3 $\left(344 \mathrm{~K} \leq \theta_{\mathrm{det}}<348 \mathrm{~K}\right)$ and DET2 distributions. (d) As in panel (a) but for the difference between the DET4 $\left(\theta_{\mathrm{det}} \geq 348 \mathrm{~K}\right)$ and DET2 distributions.

at lower $\theta_{\text {det }}$, particularly in the DET1 bin. Also, convection tends to influence progressively drier areas as $\theta_{\text {det }}$ increases. Both of these results are likely partially due to horizontal advection away from the convective source during subsidence. The 300-200 hPa analysis layer is approximately bounded in potential temperature by $340 \mathrm{~K}$ and $348 \mathrm{~K}$ (cf. Folkins et al., 2002). The trajectories analyzed here detrain well below the level of zero net radiation that comprises the base of the tropical tropopause layer, and thus will be subjected primarily to radiative cooling and subsidence following detrainment. Accordingly, detrainment from lower in the tower near $340 \mathrm{~K}$ will tend to have a very short residence time in the 300$200 \mathrm{hPa}$ layer, and will be more likely to be confined to the humid area surrounding convection before it subsides below $300 \mathrm{hPa}$. Conversely, detrainment from higher in the tower may be above $200 \mathrm{hPa}$ when the trajectory is initialized, and may enter the layer farther from the convective source. Figures 6 and 7 show that convective moistening is strongest near the convective source. Further investigation, however, shows that air detrained below $344 \mathrm{~K}$ consistently leads to larger relative moistening in all RH bins than air detrained above $344 \mathrm{~K}$ regardless of time elapsed or distance traveled. In addition, the predicted $\overline{\Delta w}$ decreases substantially as $\theta_{\text {det }}$ increases (Table 1). This decrease is unsurprising since the saturation mixing ratios encountered will also tend to decrease rapidly as $\theta_{\text {det }}$ increases (this is the first order control on water vapor changes due to convection mentioned in the Introduction). Our results thus indicate that lower detrainment heights and higher detrainment temperatures typically lead to stronger moistening downstream in both absolute and relative water vapor amount.
Figure 9 shows the LNK distribution broken down by initial IWC derived from TRMM PR reflectivities using Eq. (1). Moistening increases and drying decreases as IWC increases. The reduction of IWC due to sedimentation along a trajectory can be modeled using an e-folding time (e.g., Dessler and Sherwood, 2000; Gettelman et al., 2002). We can either assume that this e-folding time is constant across the range of IWCs considered here (which essentially amounts to an assumption that the PSDs are identical, an assumption that has already been incorporated into the calculation of IWC via Eq. 1), or that large IWCs are associated with larger sedimentation velocity and shorter e-folding times (Heymsfield and Donner , 1996). The former implies that a larger IWC in the convective detrainment means more ice to potentially hydrate the ambient environment, whereas the latter assumption implies that a larger IWC will sediment faster and thus may not provide more ice downstream. Figure 9 supports the idea that a larger initial IWC provides additional ice for sublimation downstream, thus exerting a significant influence on water vapor changes in the tropical upper troposphere. The difference between IWC4 and IWC1 persists as time elapsed and distance traveled increase, supporting the conclusion that additional ice at the location of detrainment leads to enhanced moistening downstream.

Our additional diagnostics are also consistent with this interpretation. As IWC increases, $\mathcal{F}_{-l g}$ decreases and $\mathcal{F}_{+l g}$, the predicted $\overline{\Delta w}$, and the RH threshold below which moistening is more probable than drying all increase monotonically (Table 1). $\mathcal{F}_{+}$(the fraction of scenes for which $\langle\Delta w\rangle>0$ ) is greater for larger IWC up to about $90 \% \mathrm{RH}$, at which point the lines converge and the relationship is reversed (Fig. 11a). 


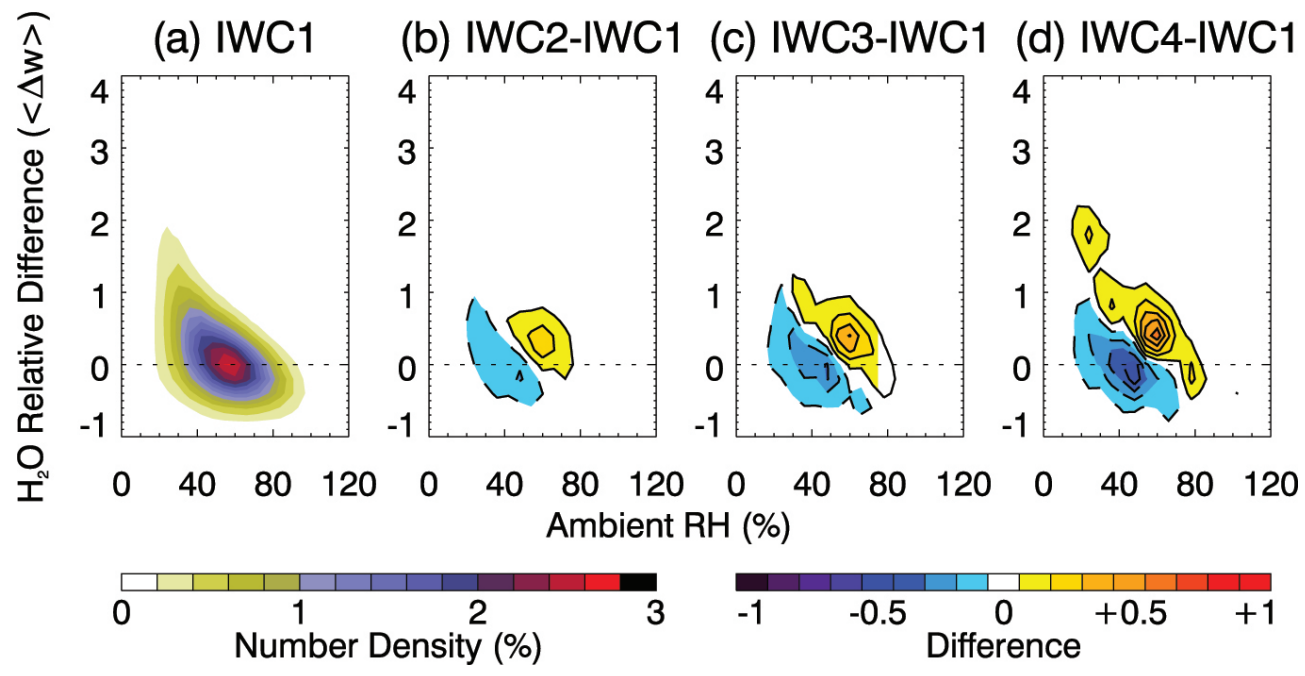

Fig. 9. (a) As in Fig. 1a, but for trajectories with estimated TRMM IWC $\leq 2 \mathrm{~g} \mathrm{~m}^{-3}$ (IWC1). (b) As in Fig. 1b, but for the difference between IWC2 $\left(2 \mathrm{~g} \mathrm{~m}^{-3}<\mathrm{IWC} \leq 3 \mathrm{~g} \mathrm{~m}^{-3}\right)$ and IWC1 distributions. (c) As in panel (b), but for the IWC $3\left(3 \mathrm{~g} \mathrm{~m}^{-3}<\mathrm{IWC} \leq 4 \mathrm{~g} \mathrm{~m}^{-3}\right)$ and IWC1 distributions. (d) As in panel (b), but for the IWC4 (IWC $>4 \mathrm{~g} \mathrm{~m}^{-3}$ ) and IWC1 distributions.

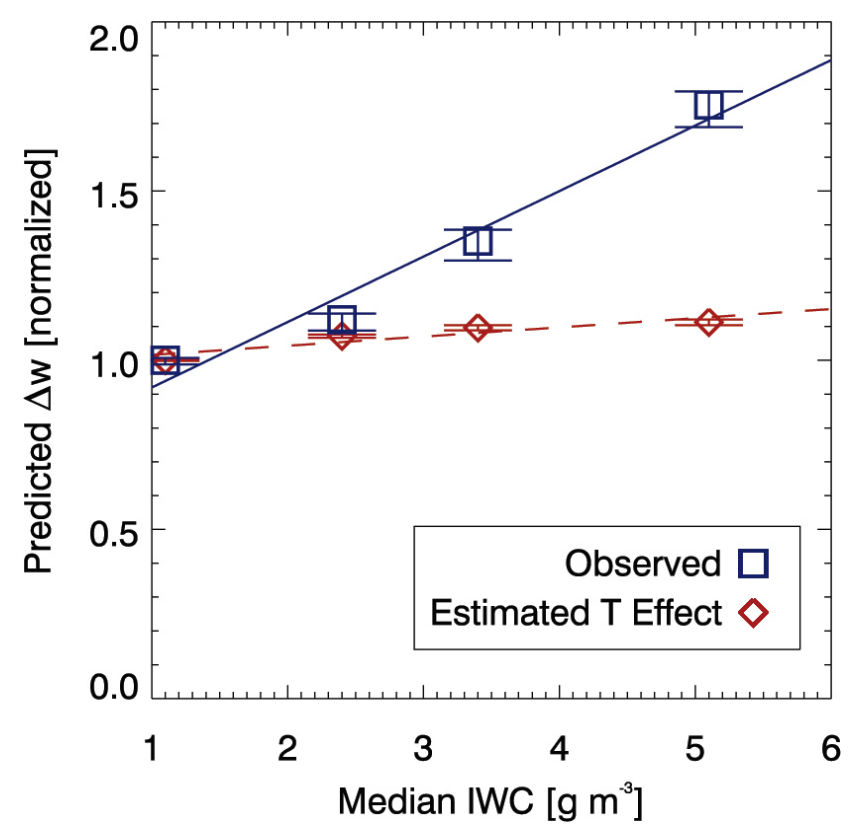

Fig. 10. Predicted water vapor change $(\overline{\Delta w})$ for the IWC1 through IWC4 distributions, normalized by $\overline{\Delta w}$ for the IWC1 distribution. Squares and blue solid line show normalized $\overline{\Delta w}$ for the observed distributions; diamonds and red dashed line show normalized $\overline{\Delta w}$ for the distributions calculated if all scenes are assumed to go to saturation (i.e., the estimated effect of the temperature differences between IWC1 and IWC4). Error bars indicate the 95\% confidence interval.

Although the statistical significance of these differences is relatively low $(60 \%$ to $80 \%$ confidence that IWC4 and IWC1 are different, depending on the bin), this suggests that additional IWC may play a role in suppressing supersaturation in convective regions. The predicted $\overline{\Delta w}$ is greater for greater IWC throughout the range of RH with sufficient sample size.

Because the ice water content of convection tends to decrease with height in the upper troposphere, it is possible that the observed relationship between increased IWC and enhanced moistening is the result of warmer temperatures rather than additional ice. To explore this, we have calculated four additional PDFs using the same points as IWC1 through IWC4, but ignoring the observed $w_{\text {aft }}$ and assuming that the local water vapor mixing ratio always goes to saturation $\left(w_{\text {aft }}=w^{\#}\right)$. Since saturation mixing ratios are a function of temperature, these distributions should isolate the influence of detrainment temperature. Figure 10 shows the predicted $\overline{\Delta w}$ for both groups of IWC PDFs, normalized by $\overline{\Delta w}$ for the appropriate IWC1 distribution. The slope of the expected change between IWC1 and IWC4 due solely to temperature differences is much less than the observed change. This result suggests that the correlation between increased IWC and enhanced moistening is real, and is not just an artifact of correlated temperature differences. As an additional check, we have examined the difference between PDFs associated with IWC $\geq 2 \mathrm{~g} \mathrm{~m}^{-3}$ and IWC $\leq 1 \mathrm{~g} \mathrm{~m}^{-3}$, binned into $0.1 \mathrm{~K}$ detrainment potential temperature bins around $343 \mathrm{~K}$, $344 \mathrm{~K}, 345 \mathrm{~K}, 346 \mathrm{~K}$. The results of this analysis (not shown) also indicate that larger IWCs are associated with enhanced downstream moistening regardless of $\theta_{\text {det }}$.

Figure 11a shows $\mathcal{F}_{+}$for the IWC1, IWC2, IWC3, IWC4, and GRD distributions, binned by ambient RH. Between $20 \% \mathrm{RH}$ and $80 \% \mathrm{RH}$, a larger IWC leads to a greater likelihood of moistening. This is illustrated by the ratio of the 

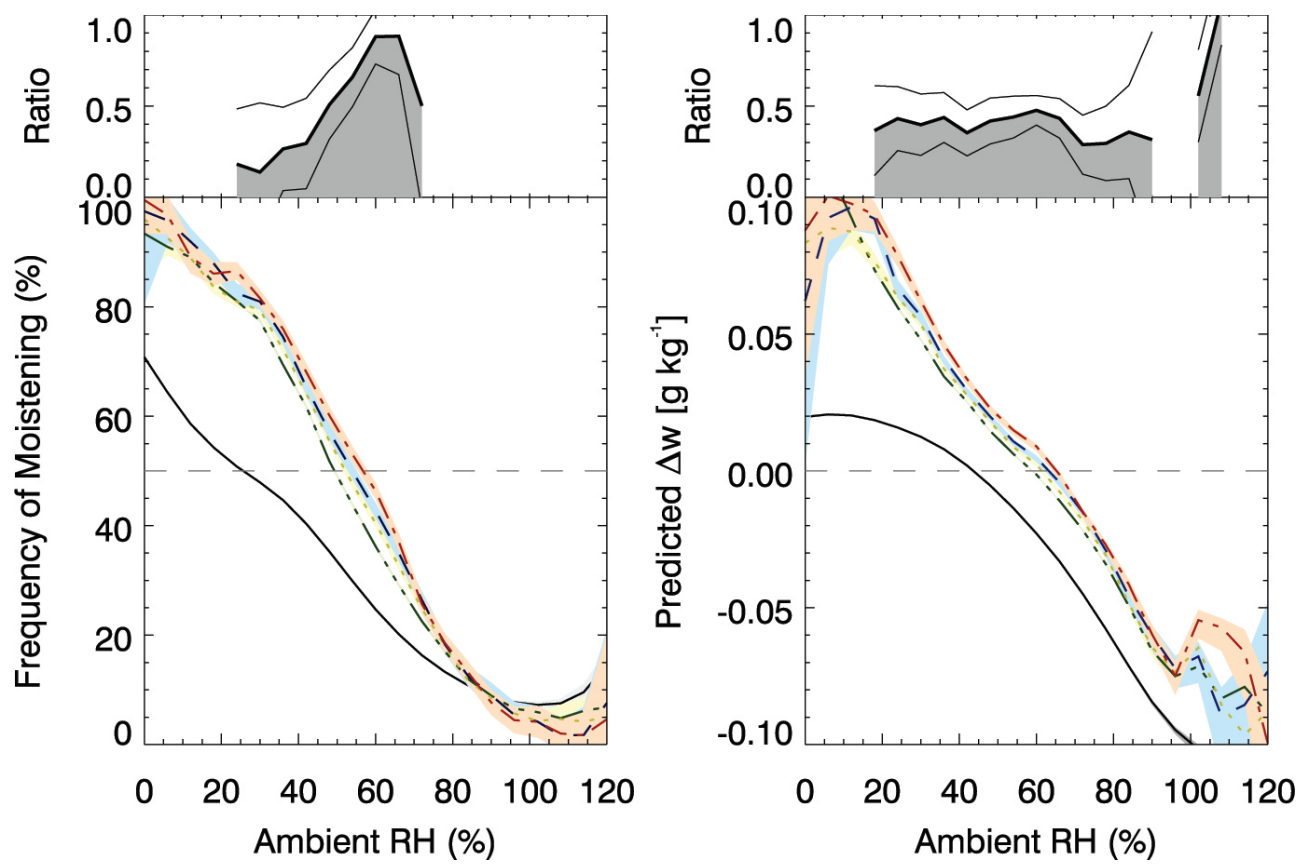

Fig. 11. (a) Frequency of moistening $\left(\mathcal{F}_{+}\right)$for the GRD (black solid line), IWC1 (green dash-dot-dot-dot line), IWC2 (yellow dotted line), IWC3 (blue dashed line), and IWC4 (red dash-dot line) distributions, shown as a function of ambient RH. (b) As in panel (a) but for predicted change in water vapor $(\overline{\Delta w})$. Shading denotes $95 \%$ confidence interval. The panel above each graph shows the ratio of the difference between the IWC4 and IWC1 lines and to the difference between the IWC1 and GRD lines for all bins for which the IWC1 and IWC4 confidence intervals do not overlap.

difference between $\mathcal{F}_{+}$for IWC4 and $\mathcal{F}_{+}$for IWC1 and the difference between $\mathcal{F}_{+}$for IWC1 and $\mathcal{F}_{+}$for GRD, which is plotted above the line graph. This ratio varies between $0.14 \pm 0.38$ for the $30-36 \%$ RH bin to $0.88 \pm 0.15$ for the 60 $66 \%$ RH bin. The difference between the median IWCs for these two distributions is approximately $4.0 \mathrm{~g} \mathrm{~m}^{-3}$ (Fig. 10); this additional ice results in a $14-88 \%$ increase in the likelihood of moistening by convection relative to the background state.

The predicted change in water vapor $(\overline{\Delta w})$ for each IWC distribution is plotted as a function of ambient RH in Fig. 11b. A larger IWC is associated with a larger increase in water vapor between $20 \% \mathrm{RH}$ and $90 \% \mathrm{RH}$. Through much of this interval, the $\overline{\Delta w}$ values calculated from all four IWC distributions are statistically distinct at the $95 \%$ level. The ratio of the difference between the IWC4 and IWC 1 lines to the difference between the IWC1 and GRD lines is also shown in Fig. 11b. The additional IWC corresponds to a $29-48 \%$ increase in the magnitude of moistening, about an additional $0.006-0.01 \mathrm{~g} \mathrm{~kg}^{-1}$. Although this additional moistening is small relative to the additional ice water content, it is significant (about $6-10 \%$ ) when compared to the mean upper tropospheric mass mixing ratio of water vapor $\left(\sim 0.1 \mathrm{~g} \mathrm{~kg}^{-1}\right)$.

\section{Discussion}

The results of this study show that convection acts primarily as a moisture source in the tropics. Through most of the tropics, convective moistening contributes an additional $0.01 \mathrm{~g} \mathrm{~kg}^{-1}$ of water vapor relative to background changes. This corresponds to a moistening influence of about $10 \%$ of the ambient water vapor amount.

The moistening influence of convection is strongly modulated by the ambient RH. When RH is low, convection is very effective at moistening the environment, and often causes very large increases in water vapor. When the ambient air is humid but subsaturated, the frequency of moistening is substantially reduced, but convection still generally acts to offset subsidence drying. When the ambient air is supersaturated, convection generally dries the environment. At all values of $\mathrm{RH}$, convection tends to nudge the environment toward saturation.

Large relative increases in UTWV most often occur in transition zones where the convective frequency is neither very high nor very low $(0.01 \% \leq \mathrm{FDC} \leq 0.1 \%$, where FDC is defined as active convection at $10 \mathrm{~km}$ observed by TRMM PR). Locations with very frequent convection (FDC $>0.1 \%$ ) rarely experience large increases, because these environments are already quite humid. Although locations where convection is rare $(\mathrm{FDC}<0.01 \%)$ also rarely experience large 
increases, when air that is recently detrained from convection encounters these regions it often causes large relative increases in UTWV.

Accurately characterizing the water vapor distribution in the subtropical upper troposphere is crucial for determining the water vapor feedback to climate change (Sun and Lindzen, 1993; Pierrehumbert, 1995). While some studies have argued that detrainment of ice from tropical convection is influential in determining subtropical upper tropospheric humidity (e.g., Sun and Lindzen, 1993; Spencer and Braswell, 1997), others have concluded that subtropical UTWV is determined primarily by large-scale advection and condensation (Emanuel and Pierrehumbert, 1995; Salathé and Hartmann, 1997; Pierrehumbert, 1998). Our analysis indicates that detrainment of ice from tropical deep convection plays only a very limited role in determining water vapor changes in the subtropical upper troposphere. The results of our analysis are consistent with the conclusion of Ryoo et al. (2008) that water vapor variability in much of the subtropical upper troposphere is influenced more by intrusions of dry stratospheric air than by advection from recent tropical convection.

Continental convection in the tropics is generally more intense than its maritime counterpart, with stronger updraft speeds, greater IWCs, more lightning, and a deeper penetration of the cloud top (cf. Petersen and Rutledge, 2001). This dissimilarity extends to downstream water vapor changes as well. Convective moistening is enhanced for continental convection relative to maritime convection. A similar but weaker enhancement is also observed during July and October relative to January and April. These two relationships may be interconnected, since July and October also show enhanced continental convective activity relative to January and April. We have mentioned several possible explanations, including enhanced wave-induced mixing, larger amounts of detrained ice, and smaller ice particle sizes. Our results indicate that larger amounts of ice are associated with enhanced moistening. We have not explicitly investigated how smaller ice particle sizes or enhanced wave activity might contribute.

The temporal and spatial limits of convective moistening implied by our results agree well with the lifetimes of tropical detrainment cirrus. Our estimates $(24-48 \mathrm{~h}$ and $600-$ $1500 \mathrm{~km}$ ) are generally longer than the detrainment cirrus lifetimes reported by Luo and Rossow (2004) (19-30 $\pm 16 \mathrm{~h}$ and $600-1000 \mathrm{~km})$. This is consistent with their observation that anomalies of enhanced moisture persist for several hours after the cirrus dissipate. The moistening potential of convectively detrained air appears to be more strongly controlled by the time elapsed since detrainment, rather than the distance traveled.

The role of ice in determining UTWV in the tropics has been vigorously debated for more than a decade (e.g., Sun and Lindzen, 1993; Emanuel and Pierrehumbert, 1995; Sherwood, 1996; Salathé and Hartmann, 1997; Dessler and Sherwood, 2000; Dessler and Minschwaner, 2007). This de- bate has typically revolved around model results, particularly whether models require that ice microphysics be invoked to accurately determine the distribution of UTWV. Our results provide an observational context to this debate. In particular, we have shown that the amount of ice detraining from convection has a significant influence on downstream water vapor changes in the tropics. This influence is observed in both absolute and relative changes, and persists as time elapsed and distance traveled grows. In particular, the IWC4 distribution is comprised of observations with an estimated median IWC that is $4 \mathrm{~g} \mathrm{~m}^{-3}$ larger than that of IWC1 at the initial point of detrainment. The values in Table 1 indicate that this additional ice is associated with a $(72 \pm 9) \%$ increase in the predicted change in water vapor $(\overline{\Delta w})$, a $(24 \pm 14) \%$ increase in the likelihood of a doubling in water vapor $\left(\mathcal{F}_{+l g}\right)$, and a $(9 \pm 31) \%$ decrease in the likelihood of a halving in water vapor $\left(\mathcal{F}_{-l g}\right)$. Figure 11 further shows a $10-90 \%$ increase in the overall likelihood of moistening $\left(\mathcal{F}_{+}\right)$and a $30-50 \%$ increase in the magnitude of moistening relative to the convective events comprising IWC1. The relevance of ice water content to water vapor changes in the tropics is in marked contrast to the lack of influence exerted by tropically detrained ice in the subtropical upper troposphere.

Soden (2004) observed that the peak value of downstream humidity is strongly correlated with the extent of the convective anvil, and noted that this means that either the detrained vapor increases as anvil ice increases or the anvil ice is sublimating. Our analysis shows a similar relationship between IWC and downstream vapor changes. The amount of detrained vapor is generally determined by the detrainment temperature. We have shown that the relationship between IWC and stronger downstream moistening holds regardless of detrainment temperature. This strongly suggests that the sublimation of anvil ice constitutes a significant source of UTWV downstream from convection.

We note that there are several uncertainties associated with the calculation of IWC in this analysis; however, we do not expect these to alter the qualitative nature of the results. These uncertainties fall into three categories. First, radar reflectivities of $20 \mathrm{dBZ}$ should be well below cloud top, thus a significant amount of convective anvil ice cloud above $10 \mathrm{~km}$ remains unaccounted for. Although it is not clear from our results whether the IWC- $\langle\Delta w\rangle$ relationship extrapolates to lower IWCs, the results obtained using the incremental IWC bins at high IWCs are strongly suggestive. At the very least, a greater IWC is associated with stronger moistening downstream of the most intense tropical deep convection. Second, there are uncertainties in the in situ microphysical observations used to develop the underlying mass-dimension relationship in the IWC- $Z_{e}$ relationship. We estimate about a factor of two uncertainty in the chosen relationship based on varying the mass-dimension relationship within a reasonable range. We have also examined four other $I W C-Z_{e}$ relationships that were derived in ways that did not rely on these observations, and found that all of them were qualitatively 
similar. Third, there is an error associated with applying one IWC- $Z_{e}$ relationship uniformly to all tropical convective clouds. Although the available in situ microphysical observations are insufficient to fully evaluate this error, the analysis conducted by Protat et al. (2007) suggests that it is reasonable to apply one relationship in the tropics, provided that another is used in the midlatitudes.

Significant uncertainties remain in current climate model treatments of convectively detrained water vapor and ice (Del Genio et al., 2005; Randall et al., 2007; Waliser et al., 2009). Much of the physics of these interactions occurs at spatial and time scales that cannot be resolved at current GCM resolutions. These parameterizations require observational constraints for evaluation and improvement. The method and results presented here can be readily adapted to provide such observational constraints. The method is constructed in such a way as to mimic the evolution of water vapor in GCM grid boxes, and is presented statistically for more relevant comparison with climate model results. The GRD distribution can be derived for any model using daily gridded model results, such as are available through the Intergovernmental Panel on Climate Change's Fourth Assessment Report model results archive. The LNK distribution and various subsets can be recreated by generating subdaily output and running trajectories using modeled winds and heating rates. Points of agreement and contrast between similarly aggregated distributions can thus inform future development of model parameterizations of deep convective detrainment. In particular, such comparisons and subsequent testing may help to constrain the extent to which ice microphysics must be included in a model to achieve sufficient agreement with the observed distributions.

\section{Conclusions}

We have presented a concise and compact way to represent changes in tropical UTWV, both for locations directly linked to convection and locations that may or may not be linked to convection. Our results confirm that the moistening influence of convectively detrained air outweighs its drying influence, whereas drying and moistening are largely balanced for air masses not connected to convection. The moistening influence of detrained air is enhanced for continental convection relative to maritime convection.

Convective moistening occurs primarily within $300 \mathrm{~km}$ and within the first $12 \mathrm{~h}$ after detrainment. The estimated duration $(\sim 24-48 \mathrm{~h})$ and spatial extent $(600-1500 \mathrm{~km})$ of the convective influence agree well with the lifetimes and travel distances of detrainment cirrus clouds (Luo and Rossow, 2004).

The strongest moistening and drying events in the tropics occur most often in the relatively dry transitional regions where convective frequency is neither very high nor very low. These regions are crucial for determining the water vapor feedback, since outgoing longwave radiation is highly sensitive to water vapor changes in locations where the mean upper tropospheric relative humidity is low (Shine and Sinha, 1991; Pierrehumbert, 1995).

Recent tropical convection appears to exert very little influence on water vapor changes in the subtropical upper troposphere. Large-scale mixing and variability associated with the subtropical jet appear to play a much more prominent role in this region.

The temperature of detrainment has the largest impact on local water vapor changes in the tropics; however, we have also found that larger ice water contents provide additional moistening downstream. This strongly suggests that the sublimation of anvil ice constitutes a significant source of UTWV downstream from convection.

These results may potentially provide a valuable observational constraint for climate model representations of deep convective detrainment. The statistical formulation of the results lends itself well to comparisons with similarly processed model output. Future work will focus on such comparisons with several widely-used climate models.

Acknowledgements. We acknowledge the Goddard Earth Science and Technology Center's Graduate Student Summer Program, which supported the initial work that led to this study. We also thank Andrew Dessler and Walter Petersen for useful discussions, Annemarie Eldering and Ed Olsen for clarifying aspects of the AIRS data, and Mark Schoeberl for providing assistance with the trajectory model. This work was supported by the NASA Global Energy and Water Cycle program, NASA Earth System Science research using data and products from Terra, Aqua and ACRIMSAT NNG04GK90G and the NASA Aura Program at the Georgia Institute of Technology.

Edited by: T. Röckmann

\section{References}

Aumann, H. H., Chahine, M. T., Gautier, C., Goldberg, M. D., Kalnay, E., McMillin, L. M., Revercomb, H., Rosenkranz, P. W., Smith, W. L., Staelin, D. H., Strow, L. L., and Susskind, J.: AIRS/AMSU/HSB on the Aqua mission: design, science objectives, data products, and processing systems, IEEE T. Geosci. Remote, 41, 253-264, 2003.

Chaudhuri, P. and Marron, J. S.: SiZer for exploration of structure in curves, J. Am. Stat. Assoc., 94, 807-823, 1999.

Deierling, W., Petersen, W. A., Latham, J., Ellis, S., and Christian, H. J.: The relationship between lightning activity and ice fluxes in thunderstorms, J. Geophys. Res., 113, D15210, doi: 10.1029/2007JD009700, 2008.

Del Genio, A. D., Kovari, W., Yao, M.-S., and Jonas, J.: Cumulus microphysics and climate sensitivity, J. Climate, 18, 2376-2386, 2005.

Dessler, A. E. and Minschwaner, K.: An analysis of the regulation of tropical tropospheric water vapor, J. Geophys. Res., 112, D10120, doi:10.1029/2006JD007683, 2007. 
Dessler, A. E. and Sherwood, S. C.: Simulations of tropical upper tropospheric humidity, J. Geophys. Res., 105, 20 155-20 163, 2000.

Divakarla, M. G., Barnet, C. D., Goldberg, M. D., McMillin, L. M., Maddy, E., Wolf, W., Zhou, L., and Liu, X.: Validation of Atmospheric Infrared Sounder temperature and water vapor retrievals with matched radiosonde measurements and forecasts, J. Geophys. Res., 111, D09515, doi:10.1029/2005JD006116, 2006.

Emanuel, K.: Atmospheric Convection, Oxford University Press, New York, USA, 1994.

Emanuel, K. A. and Pierrehumbert, R. T.: Microphysical and dynamical control of tropospheric water vapor, in: Clouds, Chemistry, and Climate, edited by: Crutzen, P. J. and Ramanathan, V., Springer, New York, USA, 17-28, 1995.

Folkins, I., Kelly, K. K., and Weinstock, E. M.: A simple explanation for the increase in relative humidity between 11 and $14 \mathrm{~km}$ in the tropics, J. Geophys. Res., 107(D23), 4736, doi:10.1029/2002JD002185, 2002.

Fu, R., Del Genio, A. D., and Rossow, W. B.: Influence of ocean surface conditions on atmospheric vertical thermodynamic structure and deep convection, J. Climate, 7, 1092-1108, 1994.

Fuenzalida, H. A., Sánchez, R., and Garreaud, R. D.: A climatology of cutoff lows in the Southern Hemisphere, J. Geophys. Res., 110, D18101, doi:10.1029/2005JD005934, 2005.

Garreaud, R. D. and Wallace, J. M.: Summertime incursions of midlatitude air into subtropical and tropical South America, Mon. Weather Rev., 126, 2713-2733, 1998.

Gettelman, A., Randel, W. J., Wu, F., and Massie, S. T.: Transport of water vapor in the tropical tropopause layer, Geophys. Res. Lett., 29(1), 1009, doi:10.1029/2001GL013818, 2002.

Gettelman, A., Weinstock, E. M., Fetzer, E. J., Irion, F. W., Eldering, A. E., Richard, E. C., Rosenlof, K. H., Thompson, T. L., Pittman, J. V., Webster, C. R., and Herman, R. L.: Validation of Aqua satellite data in the upper troposphere and lower stratosphere with in situ aircraft instruments, Geophys. Res. Lett., 31, L22107, doi:10.1029/2004GL020730, 2004.

Gettelman, A., Collins, W. D., Fetzer, E. J., Eldering, A. E., Irion, F. W., Duffy, P. B., and Bala, G.: Climatology of uppertropospheric relative humidity from the Atmospheric Infrared Sounder and implications for climate, J. Climate, 19, 6104-6121, doi:10.1175/JCLI3956.1, 2006.

Hagan, D. E., Webster, C. R., Farmer, C. B., May, R. D., Herman, R. L., Weinstock, E. M., Christensen, L. E., Lait, L. R., and Newman, P. A.: Validating AIRS upper atmosphere water vapor retrievals using aircraft and balloon in situ measurements, Geophys. Res. Lett., 31, L21103, doi:10.1029/2004GL020302, 2004.

Heymsfield, A. J., and Donner, L.: A scheme for parameterizing ice-cloud water content in general circulation models, J. Atmos. Sci., 47, 1865-1877, 1996.

Heymsfield, A. J., Bansemer, A., Schmitt, C., Twohy, C., and Poellot, M. R.: Effective ice particle densities derived from aircraft data, J. Atmos. Sci., 61, 982-1003, 2004.

Heymsfield, A. J., Bansemer, A., Durden, S. L., Herman, R. L., and Bui, T.: Ice microphysics observations in hurricane Humberto: Comparison with non-hurricane-generated ice cloud layers, J. Atmos. Sci., 63, 288-308, doi:10.1175/JAS3603.1, 2006.

Heymsfield, G. M., Geerts, B., and Tian, L.: TRMM Precipitation Radar reflectivity profiles compared with high-resolution air- borne and ground-based measurements, J. Appl. Meteorol., 39, 2080-2102, doi:10.1175/1520-0450(2001)040〈2080:TPRRPA〉 2.0.CO;2, 2000.

Kentarchos, A. S., Davies, T. D., and Terefos, C. S.: A low latitude stratospheric intrusion associated with a cut-off low, Geophys. Res. Lett., 25, 67-70, 1998.

Kummerow, C., Barnes, W., Kozu, T., Shuie, J., and Simpson, J.: The Tropical Rainfall Measuring Mission (TRMM) sensor package, J. Atmos. Ocean. Tech., 15, 809-817, 1998.

Lane, T. P., Reeder, M. J., and Clark, T. L.: Numerical modeling of gravity wave generation by deep tropical convection, J. Atmos. Sci., 58, 1249-1274, 2001.

Luo, Z. and Rossow, W. B.: Characterizing tropical cirrus life cycle, evolution and interaction with upper-tropospheric water vapor using Lagrangian trajectory analysis of satellite observations, J. Climate, 17, 4541-4563, 2004.

Luo, Z., Kley, D., Johnson, R. H., and Smit, H.: Ten years of measurements of tropical upper-tropospheric water vapor by MOZAIC: Part I: variability, transport, and relation to deep convection, J. Climate, 20, 418-435, doi:10.1175/JCLI3997.1, 2007.

McCormack, J. P., Fu, R., and Read, W. G.: The influence of convective outflow on mixing ratios in the tropical upper troposphere: and analysis based on UARS MLS measurements, J. Atmos. Sci., 24, 241-259, 2000.

Nesbitt, S. W. and Zipser, E. J.: The diurnal cycle of rainfall and convective intensity according to three years of TRMM measurements, J. Climate, 16, 1456-1475, doi:10.1175/ 1520-0442(2003)016〈1456:TDCORA \2.0.CO;2, 2003.

Petersen, W. A. and Rutledge, S. A.: Regional variability in tropical convection: Observations from TRMM, J. Climate, 14, 35663586, 2001.

Pierrehumbert, R. T.: Thermostats, radiator fins, and the local runaway greenhouse, J. Atmos. Sci., 52, 1784-1806, 1995.

Pierrehumbert, R. T.: Lateral mixing as a source of subtropical water vapor, Geophys. Res. Lett., 25, 151-154, 1998.

Protat, A., Delanoë, J., Bouniol, D., Heymsfield, A. J., Bansemer, A., and Brown, P.: Evaluation of ice water content retrievals from cloud radar reflectivity and temperature using a large airborne in situ microphysical database, J. Appl. Meteorol. Clim., 46, 557-572, doi:10.1175/JAM2488.1, 2007.

Randall, D. A., Wood, R. A., Bony, S., Colman, R., Fichefet, T., Fyfe, J., Kattsov, V., Pitman, A., Shukla, J., Srinivasan, J., Stouffer, R. J., Sumi, A., and Taylor, K. E.: Climate Models and Their Evaluation, in: Climate Change 2007: The Physical Science Basis. Contribution of Working Group I to the Fourth Assessment Report of the Intergovernmental Panel on Climate Change, edited by: Solomon, S., Qin, D., Manning, M., Chen, Z., Marquis, M., Averyt, K. B., Tignor, M., and Miller, H. L., Cambridge University Press, Cambridge, UK and New York, NY, USA, 589662, 2007.

Rapp, A. D., Kummerow, C., Berg, W., and Griffith, B.: An evaluation of the proposed mechanism of the adaptive infrared iris hypothesis using TRMM VIRS and PR measurements, J. Climate, 18, 4185-4194, doi:10.1175/JCLI3528.1, 2005.

Rosenfield, J. E., Newman, P. A., and Schoeberl, M. R.: Computations of diabatic descent in the stratospheric polar vortex, J. Geophys. Res., 99, 16677-16689, 1994.

Ryoo, J.-M., Waugh, D. W., and Gettelman, A.: Variability of sub- 
tropical upper tropospheric humidity, Atmos. Chem. Phys., 8, 2643-2655, 2008,

http://www.atmos-chem-phys.net/8/2643/2008/.

Salathé, E. P. and Hartmann, D. L.: A trajectory analysis of tropical upper-tropospheric moisture and convection, J. Climate, 10, 2533-2547, 1997.

Schoeberl, M. R. and Sparling, L.: Trajectory modeling, in: Diagnostic Tools in Atmospheric Physics, vol. 124, Proceedings of the International School of Physics Enrico Fermi, edited by: Fiocco, G. and Visconti, G., 289-306, IOS Press, Amsterdam, The Netherlands, 1995.

Sherwood, S. C.: Maintenance of the free-tropospheric tropical water vapor distribution. Part II: Simulation by large-scale advection, J. Climate, 9, 2919-2934, 1996.

Sherwood, S. C.: A microphysical connection among biomass burning, cumulus clouds, and stratospheric moisture, Science, 295, 1272-1275, 2002.

Shine, K. P. and Sinha, A.: Sensitivity of the Earth's climate to height-dependent changes in the water vapour mixing ratio, Nature, 354, 382-384, doi:10.1038/354382a0, 1991.

Soden, B. J.: The impact of tropical convection and cirrus on upper tropospheric humidity: A Lagrangian analysis of satellite measurements, Geophys. Res. Lett., 31, L20104, doi:10.1029/ 2004GL020980, 2004.

Soden, B. J. and Fu, R.: A seasonal analysis of deep convection, upper-tropospheric humidity, and the greenhouse effect, J. Climate, 8, 2333-2351, 1995.

Soden, B. J. and Held, I. M.: An assessment of climate feedbacks in coupled ocean-atmosphere models, J. Climate, 19, 3354-3360, doi:10.1175/JCLI3799.1, 2006.

Spencer, R. W. and Braswell, W. D.: How dry is the tropical free troposphere? Implications for global warming theory, B. Am. Meteor. Soc., 78, 1097-1106, 1997.
Sprenger, M., Maspoli, M. C., and Wernli, H.: Tropopause folds and crosstropopause transport: a global investigation based upon ECMWF analyses for the time period March 2000 till February 2001, J. Geophys. Res., 108, doi:10.1029/2002JD002587, 2003.

Stephens, G. L. and Greenwald, T. J.: The Earth's radiation budget and its relation to atmospheric hydrology: 2. Observations of cloud effects, J. Geophys. Res., 96, 15325-15340, 1990.

Sun, D.-Z. and Lindzen, R. S.: Distribution of tropical tropospheric water vapor, J. Atmos. Sci., 50, 1643-1660, 1993.

Susskind, J., Barnet, C. D., and Blaisdell, J. M.: Retrieval of atmospheric and surface parameters from AIRS/AMSU/HSB data in the presence of clouds, IEEE T. Geosci. Remote, 41, 390-409, 2003.

Swinbank, R. and O'Neill, A.: A stratosphere-troposphere data assimilation system, Mon. Weather Rev., 122, 686-702, 1994.

Waliser, D. E., Li, J.-L. F., Woods, C. P., Austin, R. T., Bacmeister, J., Chern, J., Del Genio, A., Jiang, J. H., Kuang, Z., Meng, H., Minnis, P., Platnick, S., Rossow, W. B., Stephens, G. L., SunMack, S., Tao, W.-K., Tompkins, A. M., Vane, D. G., Walker, C., and $\mathrm{Wu}, \mathrm{D}$.: Cloud ice: A climate model challenge with signs and expectations of progress, J. Geophys. Res., 114, D00A21, doi:10.1029/2008JD010015, 2009.

Waugh, D. W.: Impact of potential vorticity intrusions on subtropical upper tropospheric humidity, J. Geophys. Res., 110, D11305, doi:10.1029/2004JD005664, 2005.

Waugh, D. W. and Polvani, L. M.: Climatology of intrusions into the tropical upper troposphere, Geophys. Res. Lett., 27, 38573860, 2000.

Wernli, H.: A Lagrangian-based analysis of extratropical cyclones. II: A detailed case-study, Q. J. Roy Meteor. Soc., 123, 16771706, 1997. 